\title{
Executive Summary of Stroke Statistics in Korea 2018: A Report from the Epidemiology Research Council of the Korean Stroke Society
}

\author{
Jun Yup Kim, ${ }^{\text {a }}$ Kyusik Kang, ${ }^{\mathrm{b}}$ Jihoon Kang, ${ }^{\text {a }}$ Jaseong Koo, ${ }^{\mathrm{c}}$ Dae-Hyun Kim, ${ }^{\mathrm{d}}$ Beom Joon Kim, ${ }^{\mathrm{a}}$
} Wook-Joo Kim, ${ }^{\mathrm{e}}$ Eung-Gyu Kim, ${ }^{\mathrm{f}}$ Jae Guk Kim, ${ }^{\mathrm{g}}$ Jeong-Min Kim, ${ }^{\mathrm{h}}$ Joon-Tae Kim, ${ }^{\mathrm{i}}$ Chulho Kim, ${ }^{\mathrm{j}}$ Hyun-Wook Nah, ${ }^{\text {d }}$ Kwang-Yeol Park, ${ }^{\mathrm{h}}$ Moo-Seok Park, ${ }^{\mathrm{k}}$ Jong-Moo Park, ${ }^{\mathrm{b}}$ Jong-Ho Park, Tai Hwan Park, Hong-Kyun Park, ${ }^{\mathrm{m}}$ Woo-Keun Seo, ${ }^{\mathrm{n}}$ Jung Hwa Seo, ${ }^{\mathrm{f}}$ Tae-Jin Song, ${ }^{\circ}$ Seong Hwan Ahn, ${ }^{\mathrm{p}}$ Mi-Sun Oh, ${ }^{\mathrm{q}}$ Hyung Geun Oh, ${ }^{\mathrm{r}}$ Sungwook Yu, ${ }^{\mathrm{s}}$ Keon-Joo Lee, ${ }^{\mathrm{a}}$ Kyung Bok Lee, ${ }^{\mathrm{t}}$ Kijeong Lee, ${ }^{\mathrm{c}}$ Sang-Hwa Lee, ${ }^{\mathrm{j}}$ Soo Joo Lee, ${ }^{\mathrm{g}}$ Min Uk Jang, ${ }^{\mathrm{u}}$ Jong-Won Chung, ${ }^{\mathrm{n}}$ Yong-Jin Cho, ${ }^{\mathrm{m}}$ Kang-Ho Choi, ${ }^{\mathrm{i}}$ Jay Chol Choi, ${ }^{\mathrm{v}}$ Keun-Sik Hong, ${ }^{\mathrm{m}}$ Yang-Ha Hwang, ${ }^{\mathrm{w}}$ Seong-Eun Kim, ${ }^{\mathrm{a}}$ Ji Sung Lee, ${ }^{\mathrm{x}}$ Jimi Choi, ${ }^{\mathrm{y}}$ Min Sun Kim, ${ }^{\mathrm{y}}$ Ye Jin Kim, ${ }^{\mathrm{y}}$ Jinmi Seok, ${ }^{\mathrm{y}}$ Sujung Jang, ${ }^{\mathrm{y}}$ Seokwan Han, ${ }^{\mathrm{y}}$ Hee Won Han, ${ }^{\mathrm{y}}$ Jin Hyuk Hong, ${ }^{\mathrm{y}}$ Hyori Yun, ${ }^{\mathrm{y}}$ Juneyoung Lee, ${ }^{\mathrm{y}}$ Hee-Joon Bae ${ }^{\mathrm{a}}$

\footnotetext{
${ }^{a}$ Department of Neurology, Seoul National University Bundang Hospital, Seoul National University College of Medicine, Seongnam, Korea ${ }^{b}$ Department of Neurology, Nowon Eulji Medical Center, Eulji University, Seoul, Korea

'Department of Neurology, Seoul St. Mary's Hospital, College of Medicine, The Catholic University of Korea, Seoul, Korea

${ }^{\mathrm{d}}$ Department of Neurology, Dong-A University Hospital, Dong-A University College of Medicine, Busan, Korea

eDepartment of Neurology, Ulsan University Hospital, University of Ulsan College of Medicine, Ulsan, Korea

fDepartment of Neurology, Inje University Busan Paik Hospital, Inje University College of Medicine, Busan, Korea

${ }^{9}$ Department of Neurology, Eulji University Hospital, Eulji University, Daejeon, Korea

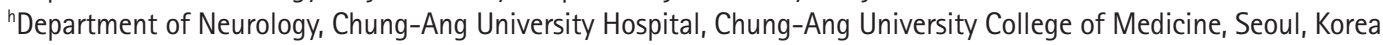

'Department of Neurology, Chonnam National University Hospital, Chonnam National University Medical School, Gwangju, Korea

jDepartment of Neurology, Hallym University Chuncheon Sacred Heart Hospital, Hallym University College of Medicine, Chuncheon, Korea

kDepartment of Neurology, Seoul Medical Center, Seoul, Korea

'Department of Neurology, Myongji Hospital, Hanyang University College of Medicine, Goyang, Korea

mDepartment of Neurology, Inje University Ilsan Paik Hospital, Inje University College of Medicine, Goyang, Korea

nDepartment of Neurology, Samsung Medical Center, Sungkyunkwan University School of Medicine, Seoul, Korea

${ }^{\circ}$ Department of Neurology, Ewha Womans University School of Medicine, Seoul, Korea

PDepartment of Neurology, Chosun University Hospital, Chosun University College of Medicine, Gwangju, Korea

${ }^{9}$ Department of Neurology, Hallym University Sacred Heart Hospital, Hallym University College of Medicine, Anyang, Korea

'Department of Neurology, Soonchunhyang University Cheonan Hospital, Soonchunhyang University College of Medicine, Cheonan, Korea

sDepartment of Neurology, Korea University Anam Hospital, Korea University College of Medicine, Seoul, Korea

tDepartment of Neurology, Soonchunhyang University Seoul Hospital, Soonchunhyang University College of Medicine, Seoul, Korea

"Department of Neurology, Hallym University Dongtan Sacred Heart Hospital, Hallym University College of Medicine, Hwaseong, Korea

'Department of Neurology, Jeju National University Hospital, Jeju National University College of Medicine, Jeju, Korea

wDepartment of Neurology, Kyungpook National University Hospital, School of Medicine, Kyungpook National University, Daegu, Korea

${ }^{\star}$ Clinical Research Center, Asan Institute for Life Sciences, Asan Medical Center, Seoul, Korea

'Department of Biostatistics, Korea University College of Medicine, Seoul, Korea
} 
Despite the great socioeconomic burden of stroke, there have been few reports of stroke statistics in Korea. In this scenario, the Epidemiologic Research Council of the Korean Stroke Society launched the "Stroke Statistics in Korea" project, aimed at writing a contemporary, comprehensive, and representative report on stroke epidemiology in Korea. This report contains general statistics of stroke, prevalence of behavioral and vascular risk factors, stroke characteristics, pre-hospital system of care, hospital management, quality of stroke care, and outcomes. In this report, we analyzed the most up-to-date and nationally representative databases, rather than performing a systematic review of existing evidence. In summary, one in 40 adults are patients with stroke and 232 subjects per 100,000 experience a stroke event every year. Among the 100 patients with stroke in 2014, 76 had ischemic stroke, 15 had intracerebral hemorrhage, and nine had subarachnoid hemorrhage. Stroke mortality is gradually declining, but it remains as high as 30 deaths per 100,000 individuals, with regional disparities. As for stroke risk factors, the prevalence of smoking is decreasing in men but not in women, and the prevalence of alcohol drinking is increasing in women but not in men. Population-attributable risk factors vary with age. Smoking plays a role in young-aged individuals, hypertension and diabetes in middle-aged individuals, and atrial fibrillation in the elderly. About four out of 10 hospitalized patients with stroke are visiting an emergency room within 3 hours of symptom onset, and only half use an ambulance. Regarding acute management, the proportion of patients with ischemic stroke receiving intravenous thrombolysis and endovascular treatment was $10.7 \%$ and $3.6 \%$, respectively. Decompressive surgery was performed in 1.4\% of patients with ischemic stroke and in $28.1 \%$ of those with intracerebral hemorrhage. The cumulative incidence of bleeding and fracture at 1 year after stroke was $8.9 \%$ and $4.7 \%$, respectively. The direct costs of stroke were about 1.68 trillion (KRW), of which 1.11 trillion were for ischemic stroke and $\$ 540$ billion for hemorrhagic stroke. The great burden of stroke in Korea can be reduced through more concentrated efforts to control major attributable risk factors for age and sex, reorganize emergency medical service systems to give patients with stroke more opportunities for reperfusion therapy, disseminate stroke unit care, and reduce regional disparities. We hope that this report can contribute to achieving these tasks.

Keywords Stroke; Statistics; Epidemiology
Correspondence: Hee-Joon Bae Department of Neurology, Cerebrovascular Center, Seoul National University Bundang Hospital, Seoul National University College of Medicine, 82 Gumi-ro 173beon-gil, Bundang-gu, Seongnam 13620, Korea

Tel: +82-31-787-7467

Fax: +82-31-787-4059

E-mail: braindoc@snu.ac.kr

Received: November 1, 2018

Revised: November 22, 2018

Accepted: November 29, 2018

\section{Introduction}

According to the Global Burden of Diseases, Injuries, and Risk Factors Study (GBD 2010), stroke is the second most common cause of death ${ }^{1}$ and the third most common cause of disability-adjusted life years (DALYs) ${ }^{2}$ worldwide. In Korea, for a long time, stroke was the second leading cause of death after cancer. ${ }^{1}$ However, since 2012, stroke lost its second rank to heart disease. According to the annual report on the Cause of Death Statistics by Statistics Korea, 45.8 subjects per 100,000 died of cerebrovascular disease but 58.2 subjects per 100,000 died of heart disease in $2016 .^{3}$

Despite this great burden of stroke to our society, Republic of Korea has been classified as a country with no data on stroke incidence, ${ }^{4}$ although a recent attempt to summarize nationally representative data on stroke by the Korean Stroke Society and the Clinical Research Center for Stroke seemed to be successful. ${ }^{5-8}$ However, these reports were based on published data mostly and had limitations related to representativeness and comprehensiveness.

The Epidemiologic Research Council of the Korean Stroke Society was established in 2015. Its mission comprises regular publication of statistical reports on stroke epidemiology of Korea. In early 2016, the Council received the approval of the executive committee of the Korean Stroke Society to launch the "Stroke Statistics in Korea" project, aimed at writing a report on stroke epidemiology in Korea. The report consists of five parts: (1) general statistics, including incidence, prevalence, and mortality; (2) prevalence of behavioral and vascular risk factors in general and stroke populations; (3) stroke characteristics, including stroke subtypes, stroke severity, lesion locations, and involved vascular territories; (4) the pre-hospital system, hospital management, and secondary prevention; and (5) quality of stroke care, costs, and outcomes. This report (1) pro- 
vides a contemporary, comprehensive, and representative report on stroke epidemiology in Korea; (2) gives reliable resources to guide clinicians and investigators in their research; (3) helps healthcare policy makers to develop and implement healthcare plans; and (4) contributes to achieving the Vision 2020 goal of the Korean Stroke Society to reduce stroke incidence and disability by $10 \%$ within 10 years. The work group comprises a total of 40 writing group members and 11 central statistical supporting team members.

This executive summary contains key statistics of Stroke Statistics in Korea 2018. The full version of the report is available online at http://www.stroke.or.kr/bbs/?code=epidemic $1 .{ }^{9}$

\section{Methods}

To write a report on stroke epidemiology in Korea, we analyzed the most up-to-date available databases, rather than performing a systematic review of existing evidence. For the details of the databases used in this report, see Table 1-1 in Stroke Statistics in Korea 2018. ${ }^{9}$ Most of the findings were obtained from direct analysis of these databases by the statistical supporting team.

To obtain data about the general population in Korea, the Korea National Health and Nutrition Examination Survey (KNHANES) database of the Korea Centers for Disease Control and Prevention $(K C D C)$, the National Health Insurance ServiceNational Sample Cohort (NHIS-NSC) database, and the Cause of Death Statistics of Statistics Korea were used. The KNHANES is a nationwide cross-sectional survey conducted every year by KCDC. ${ }^{10}$ Each survey includes a new sample of about 10,000 individuals from non-institutionalized Korean citizens who are representative of the population. It comprises a health interview, health examination, and nutrition survey.

The NHIS-NSC database is a population-based cohort established by the NHIS. This cohort was constructed to provide representative information on Korean citizens' utilization of health services to the public and related researchers. ${ }^{11}$ In this cohort, a total of 1,025,340 subjects (2.2\% of the entire eligible population) was randomly sampled from the nationwide Korean health insurance claim database in 2002, and followed up to 2013. This database contains information on socioeconomic status, provided treatments with diagnosis codes and details of prescriptions, and health checkup results.

Regarding stroke population in Korea, the Clinical Research Collaboration for Stroke in Korea (CRCS-K) database, the Acute Stroke Quality Assessment Program (ASQAP) database, and the NHIS-CRCS-K matching database were used. The CRCS-K database is a multicenter prospective registry of stroke patients who were admitted to 16 stroke centers in Korea. ${ }^{7,8}$ Data fields of the registry cover demographics, risk factors, stroke characteristics including etiology work-ups and laboratory tests, acute stroke managements, secondary stroke prevention and outcomes.

The ASOAP is a national audit program that was conducted by the Health Insurance Review \& Assessment Service (HIRA) for the assessment of the quality of stroke care in acute care hospitals in Korea. The ASQAP database contains information on both participating institutions and patients with acute stroke who were admitted to the participating hospitals within 7 days of onset via an emergency room.

The NHIS-CRCS-K matching database is a database constructed through linkage between the NHIS claim database and the CRCS-K database. Using this linked database, we could analyze the information, which is usually not collected in clinical stroke registers, on inpatient and outpatient care (diagnosis codes, length of stay, treatments and their costs, and services received), prescriptions (drug codes, days prescribed, and daily dosage), and institutions (types of institutions, human resources, and equipment). Matching in the NHIS-CRCS-K matching database was only performed for patients who were registered into the CRCS-K and agreed with providing their information for this purpose before the revision of the act on the protection of personal information in 2015.

In case a direct approach to nationally representative data was not available, the literature was reviewed systematically.

This study was performed in accordance with the Declaration of Helsinki and its Institutional Review Board approval was exempted by the Institutional Review Board of the Seoul National University Bundang Hospital of Korea (No. X-1609-364-901) mostly because it used anonymous databases open to the public.

\section{General statistics}

Based on the 2006 report of the KCDC, the estimated crude and age- and sex-standardized incidence of stroke was 216 and 232 per 100,000 person-years, respectively, in 2004 (Table 1). ${ }^{5,12}$ Standardization was performed based on the 2005 Population and Housing Census of Korea. ${ }^{13}$ About 105,000 Korean people are presumed to experience a new stroke each year. ${ }^{5}$ When we estimated the stroke incidence using the NHIS-NSC database, the age-standardized incidence rate of first-ever stroke was 92.2 per 100,000 person-years in 2013 (Figure 1). A total of 46,495 people was assumed to have a new diagnosis of stroke (160-I64) in their lives.

The discrepancy of incidence between 2004 and 2013 implicates two possibilities about secular trends of stroke incidence in Korea: (1) a true decreasing tendency and (2) differences in meth- 
Table 1. Stroke incidence rate, prevalence, and mortality

\begin{tabular}{|c|c|}
\hline Variable & Value \\
\hline \multicolumn{2}{|c|}{ Incidence rates, all ages (per $100,000 / y r)^{*}$} \\
\hline Overall, crude & 216 \\
\hline Overall, age-standardized ${ }^{+}$ & 232 \\
\hline Male $^{+}$ & 230 \\
\hline Female $^{+}$ & 235 \\
\hline Age $_{1} \leq 54 \mathrm{yr}$ & 61 \\
\hline Age, 55-74 yr & 348 \\
\hline Age, $_{1} \geq 75 \mathrm{yr}$ & 463 \\
\hline \multicolumn{2}{|l|}{ Prevalence, age $\geq 19 \mathrm{yr}(\%)^{\dagger}$} \\
\hline Overall, crude & 1.71 \\
\hline Overall, age-standardized ${ }^{+}$ & 1.37 \\
\hline Male $^{+}$ & 1.56 \\
\hline Female $^{+}$ & 1.19 \\
\hline Age, $19-54 \mathrm{yr}$ & 0.53 \\
\hline Age, 55-74 yr & 3.72 \\
\hline $\mathrm{Age}_{1} \geq 75 \mathrm{yr}$ & 7.02 \\
\hline \multicolumn{2}{|c|}{ Mortality, all ages (per 100,000/yr) $(\%)^{\S}$} \\
\hline Overall, age-standardized" & 29.6 \\
\hline Male" & 37.4 \\
\hline Female & 23.6 \\
\hline Age, $19-54 \mathrm{yr}$ & 6.8 \\
\hline Age, 55-74 yr & 60.9 \\
\hline Age, $\geq 75 \mathrm{yr}$ & 605.1 \\
\hline
\end{tabular}

*Incidence of stroke was adopted from the 2006 Korean Center for Disease Control \& Prevention Report, ${ }_{1}^{12}$ which estimated the rates using data obtained in 2004; 'Standardization was made using the age structure of the general population in the 2005 Census of Korea; ${ }^{*}$ Prevalence of stroke was calculated using the Korea National Health and Nutrition Examination Survey database from 2013 to 2014 in the general population $\geq 19$ years of age; ${ }^{\S}$ Mortality of stroke was obtained using the Cause of Death Statistics in 2015; "Standardization was made using the age structure of the general population in the 2005 Population and Housing Census of Korea.

ods of estimating stroke incidence. When considering the decreasing trends in both stroke mortality in Korea from 2006 to 2015 (for the detailed value, see Supplemental Table 3-1 in Stroke Statistics in Korea $2018^{\circ}$ ) and stroke incidence in high-income countries from 1990 to $2010,{ }^{14}$ stroke incidence may have decreased from 2004 to 2013. However, another recent study by the KCDC reported that the crude and age-standardized stroke incidences were about 241 and 208 per 100,000 person-years, respectively, in 2014, which were similar to those in 2004, although the latter is limited by lack of validation. ${ }^{15}$ Furthermore, stroke incidence in other East-Asian countries was approximately 300 per 100,000 person-years in 2010 to $2014 .{ }^{16}$ Regarding methodological differences, several reasons could be assumed. First, stroke incidence was confirmed only by principal diagnosis codes in the

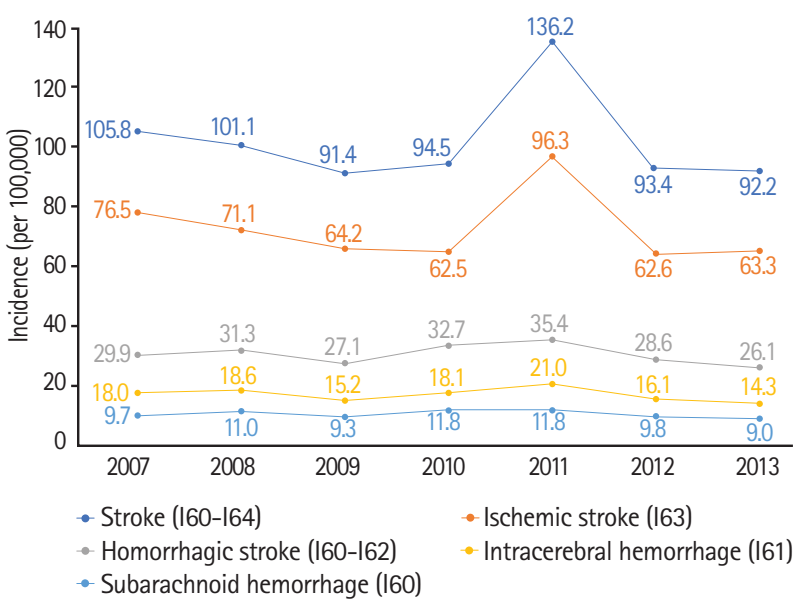

Figure 1. Age- and sex-standardized incidence rates of first-ever stroke by stroke type. Standardized rate denotes the number of patients per 100,000 population. Standardization was made based on the 2005 Population and Housing Census of Korea. Stroke incidence was evaluated using the National Health Insurance Service-National Sample Cohort (NHIS-NSC) database from 2002 to 2013.

2013's estimation and recurrent or ceased stroke cases were excluded. Second, the sampling methods and rates are different; $2.2 \%$ of the eligible population was sampled based on the claim database and the attack rates among them were used to estimate the incidence in the entire population in the 2013's estimation, while $3.0 \%$ of patients hospitalized with diagnosis codes of stroke and $8.4 \%$ of hospitals were sampled and used to calculate the incidence in the 2004's estimation. Third, the specific diagnostic algorithm was developed and validated in the 2004's estimation but not in the 2013's. In addition to these methodological considerations, the recent $K C D C$ report ${ }^{15}$ and the stroke incidence data from other Asian countries ${ }^{16}$ strongly support that the crude incidence of 216 per 100,000 person-years in the 2006's KCDC report is more representative of the actual incidence.

The crude and age-adjusted prevalence (standardized according to the 2005 Population and Housing Census of Korea) ${ }^{13}$ of stroke was estimated as $1.71 \%$ and $1.37 \%$, respectively, in Korean adults aged $\geq 19$ years in 2014 based on the KNHANES database (Table 1). A total of 692,259 patients were diagnosed as having stroke by physicians. ${ }^{9}$ In the same year, with the same definition of stroke, stroke prevalence was $2.7 \%$ in adults aged $\geq 20$ years in the United States (US), ${ }_{1}^{17}$ and the difference between Korea and the US might be attributed, at least partly, to the difference in the standard population (2005 vs. 2014). In the NHIS-NSC database, the crude prevalence rate was 2.57\% in Korean adults aged $\geq 20$ years in 2013 (for the details, see Figure 2-2 in Stroke Statistics in Korea 2018²). Stroke was defined, when estimating stroke prevalence using the NHIS-NSC database, as new assignment of principal diagnosis codes of 
I60 to I64 accompanied by a claim of brain computed tomography (CT) and/or magnetic resonance imaging (MRI). When considering the limitation of the NHIS-NSC database as claim data for reimbursement, the true prevalence lies near the figure estimated using the KNHANES database.

In the GBD study 2010, in which the World Health Organization (WHO) World Standard Population used in the latest United Nations (UN) assessment for 1998 served as a reference, ${ }^{18}$ the absolute number of prevalent stroke cases in Korea was 379,763 in $2010 .{ }^{14}$ When applying the age- and sex-specific stroke prevalence obtained from the KNHANES to the WHO World Standard Population, the estimated number of prevalent stroke cases in Korea is 451,000 , slightly higher than the provided figure in the GBD study 2010.

In subgroup analysis using the KNHANES database, the prevalence of stroke increased with age (Table 1). Across all age groups, the prevalence was higher in men than women (see Figure 2-2 in Stroke Statistics in Korea $2018^{9}$ for details).

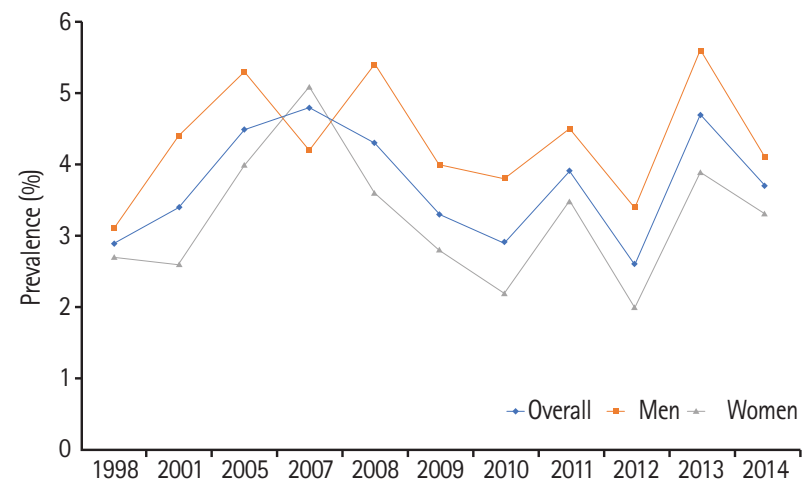

Figure 2. Secular trends of age-standardized prevalence (age $\geq 50$ years) of stroke. Standardization was made based on the 2005 Population and Housing Census of Korea. Stroke prevalence was obtained using the Korea National Health and Nutrition Examination Survey (KNHANES) database from 1998 to 2014.
Stroke prevalence in adults aged $\geq 50$ years did not show any specific secular trends between 1998 and 2014 (Figure 2). The observed variation may be explained by the limitation of stroke diagnosis in KNHANES; stroke prevalence was obtained by one simple question, "Have you ever been diagnosed with stroke by a doctor?" The steady pattern in our study was not different from that in the US. ${ }^{17}$ However, as the elderly population increases, the crude number of prevalent stroke cases also increases rapidly. ${ }^{9}$

Regarding stroke subtypes, the incidence is highest for ischemic stroke, followed by intracerebral hemorrhage (ICH) and subarachnoid hemorrhage (SAH) (Figure 1). Standardized incidence rates of stroke showed a decreasing tendency between 2007 and 2013, with the exception of 2011. A similar secular trend was observed for ischemic stroke. In case of hemorrhagic stroke (160-162), a decrease was not evident. The sharp increase of stroke incidence in 2011 might be attributed to the increase of claims with stroke diagnosis codes related to worries about curtailment according to expansion of reimbursement for brain MRI in the same year.

The age-standardized stroke mortality was 29.6 per 100,000 population in 2015 (Table 1). Standardization was performed using the age structure of general population in the 2005 Population and Housing Census of Korea. ${ }^{13}$ On average, one person died because of stroke every 35 minutes in Korea. According the recent statistical report from the American Heart Association (AHA), the age-adjusted stroke mortality in the US was 37.6 per 100,000 in $2015 .{ }^{17,19}$ The GBD study also reported higher values of stroke mortality $(60.54,104.98$, and 88.41 per 100,000 in high-income, low-income countries, and globally, respectively). ${ }^{14}$ The causes of the lower mortality than expected in Korea should be explored in future research.

Along with the global trends, stroke mortality is declining (Figure 3). ${ }^{14}$ From 2006 to 2015, the age-standardized stroke

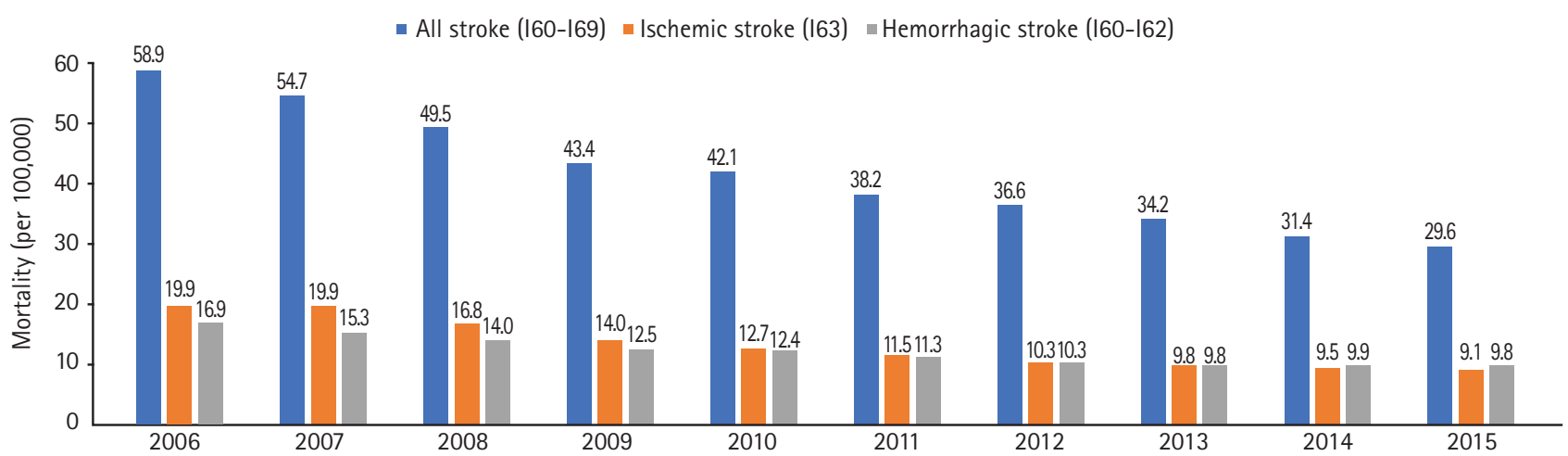

Figure 3. Secular trends of age-standardized stroke mortality by stroke type. Standardized mortality denotes the number of deaths per 100,000 population. Standardization was made based on the 2005 Population and Housing Census of Korea. Stroke mortality was estimated using Annual Reports on the Cause of Death and Population and Housing Census of Korea from 2006 to 2015. 


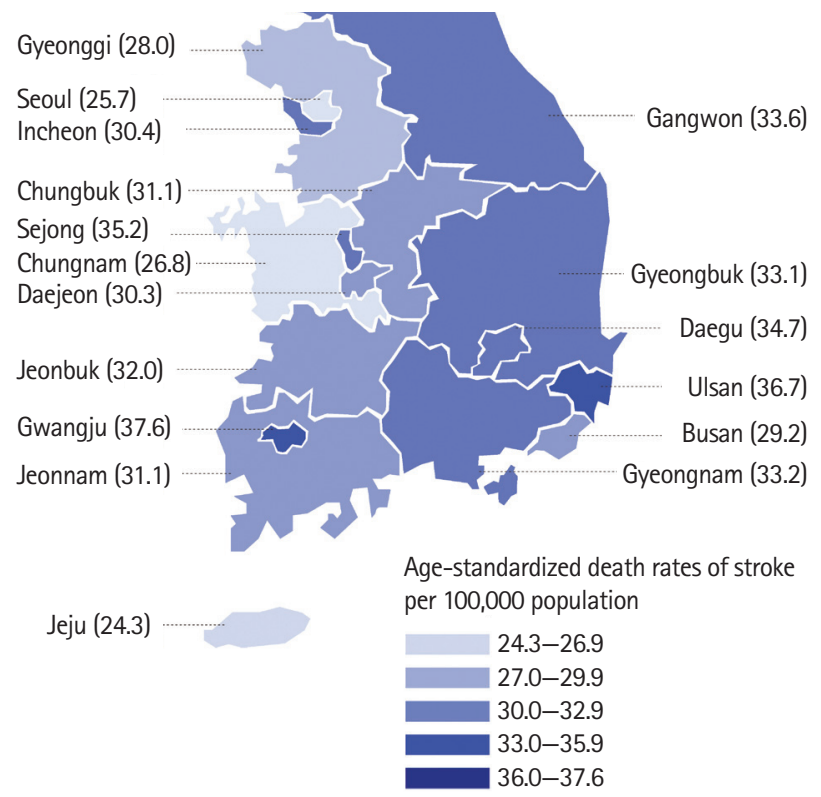

Figure 4. Age-standardized stroke mortality by region. Standardized mortality denotes the number of deaths per 100,000 population. Standardization was made based on the 2005 Population and Housing Census of Korea. Stroke mortality was estimated using Annual Reports on the Cause of Death and Population and Housing Census of Korea from 2006 to 2015.

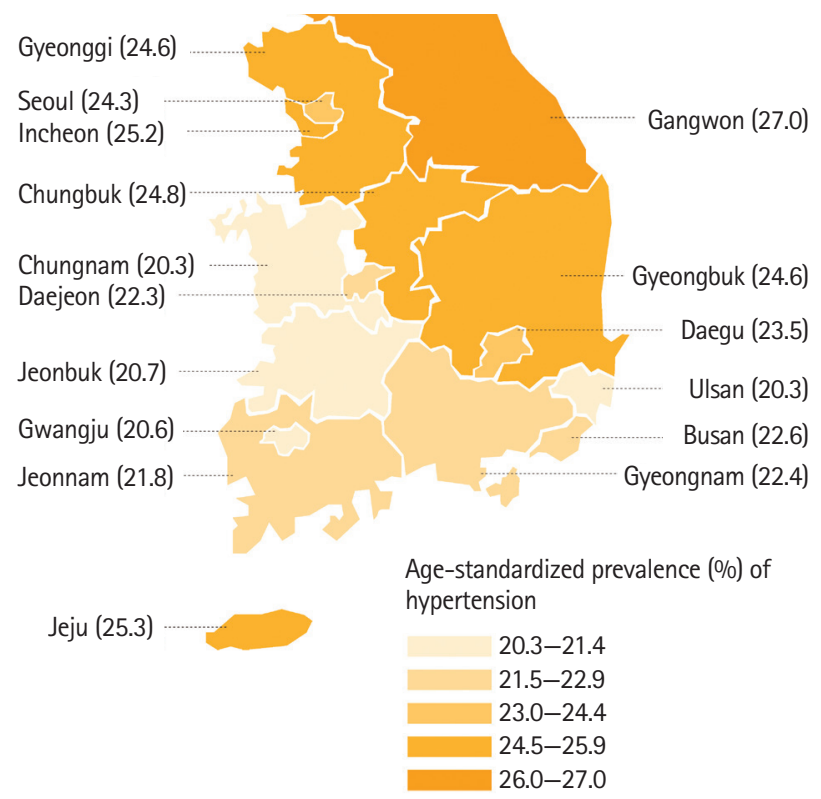

Figure 5. Age-standardized prevalence of hypertension in the general population by region. Standardization was made based on the 2005 Population and Housing Census of Korea. Prevalence of hypertension was obtained using the Korea National Health and Nutrition Examination Survey (KNHANES) database from 2010 to 2014.
Table 2. Prevalence of risk factors for stroke

\begin{tabular}{|c|c|c|}
\hline Prevalence (\%) & General population* & Stroke population $^{+}$ \\
\hline \multicolumn{3}{|l|}{ Smoking $^{\ddagger}$} \\
\hline Overall & 24.2 & 23.7 \\
\hline Male & 43.1 & 37.7 \\
\hline Female & 5.7 & 4.6 \\
\hline \multicolumn{3}{|c|}{ High-risk alcohol intake } \\
\hline Overall & 13.5 & 25.2 \\
\hline Male & 20.7 & 39.2 \\
\hline Female & 6.6 & 5.1 \\
\hline \multicolumn{3}{|l|}{ Obesity } \\
\hline Overall & 4.5 & 4.0 \\
\hline Male & 5.0 & 3.6 \\
\hline Female & 3.8 & 4.6 \\
\hline \multicolumn{3}{|l|}{ Hypertension } \\
\hline Overall & 20.5 & 67.1 \\
\hline Male & 24.1 & 64.4 \\
\hline Female & 16.7 & 70.8 \\
\hline \multicolumn{3}{|c|}{ Diabetes mellitus } \\
\hline Overall & 8.0 & 32.4 \\
\hline Male & 9.7 & 32.5 \\
\hline Female & 6.5 & 32.2 \\
\hline \multicolumn{3}{|c|}{ Hypercholesterolemia" } \\
\hline Overall & 7.8 & 7.2 \\
\hline Male & 7.4 & 6.0 \\
\hline Female & 8.3 & 8.8 \\
\hline \multicolumn{3}{|l|}{ Atrial fibrillation } \\
\hline Overall & 1.9 & 21.0 \\
\hline Male & 2.0 & 18.3 \\
\hline Female & 1.9 & 24.7 \\
\hline
\end{tabular}

*Standardization was made based on the 2005 Population and Housing Census of Korea. Prevalence of each risk factor in the general population was evaluated using the Korea National Health and Nutrition Examination Survey (KNHANES) database in 2014, except for hypercholesterolemia, which was evaluated using the KNHANES database from 2010 to 2014, and atrial fibrillation, which was evaluated using the National Health Insurance Service-National Sample Cohort database in 2013. Prevalence of risk factors in the general population was analyzed in adults $\geq 19$ years of age, except for atrial fibrillation in adults $\geq 20$ years of age due to a different source database; 'Standardization was made using the age and sex structure of the Clinical Research Collaboration for Stroke in Korea (CRCSK) database in 2014 and 2015. Prevalence of each risk factor in the stroke population was evaluated using the CRCS-K database in 2014, except for high-risk alcohol intake from January 2011 to February 2013, and hypercholesterolemia and atrial fibrillation from January 2010 to March 2015. Prevalence of risk factors in the stroke population was analyzed in all age groups; ${ }^{*}$ Smoking was defined as a current smoker with a lifetime history of smoking with 100 or more cigarettes; ${ }^{5}$ High-risk alcohol intake was defined as drinking with average alcohol consumption above 7 glasses in men (5 glasses in women) and twice or more a week; "Hypercholesterolemia was defined as total cholesterol $\geq 240 \mathrm{mg} / \mathrm{dL}$. 

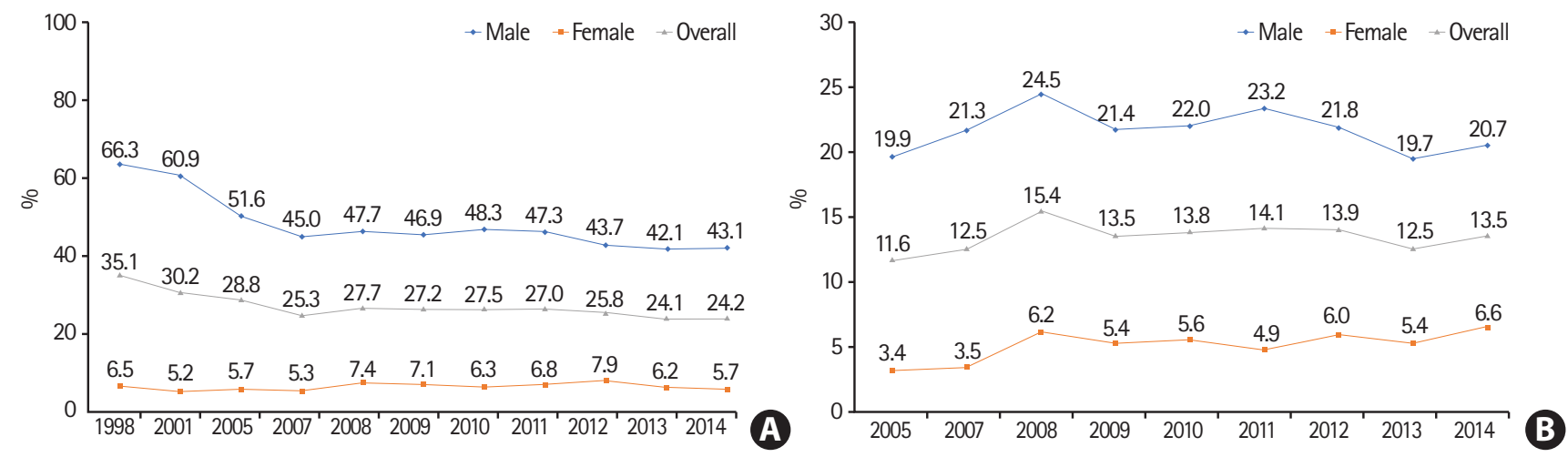

Figure 6. Prevalence of (A) current cigarette smoking* and (B) high-risk alcohol intake ${ }^{\dagger}$ in the general population (adults aged $\geq 19$ years) by sex. ${ }^{*}$ Current smoking was defined as a current smoker with a lifetime history of smoking $\geq 5$ packs (100 cigarettes). ${ }^{+} H$ igh-risk alcohol intake was defined as drinking with average alcohol consumption above 7 glasses in men ( 5 glasses in women) and twice or more a week. * These two footnotes: standardization was made based on the 2005 Population and Housing Census of Korea. Prevalence of smoking and alcohol drinking was estimated using the Korea National Health and Nutrition Examination Survey (KNHANES) database from 1998 to 2014.

mortality decreased from 58.9 to 29.6 per 100,000 population (Figure 3). The actual number of stroke deaths also declined by 18.6\% (see Supplemental Table 3-1 of Stroke Statistics in Korea $2018^{9}$ for details). In the US, from 2005 to 2015 , the agestandardized stroke mortality decreased by $21.7 \%$ and the actual number of stroke deaths declined by $2.3 \% .{ }^{17}$

Stroke mortality steeply increased with age, particularly after age 70 (Table 1). In all age groups, men showed higher mortality than women (see Table 3-1 of Stroke Statistics in Korea $2018^{9}$ for details). Regional disparities in age-standardized stroke mortality are observed, with maximum 1.5-fold differences among regions in 2015 (Figure 4). Regional disparities are also found in the US, and are known as the "stroke belt."17,20,21 The overall stroke mortality is approximately $30 \%$ higher in the stroke belt than in the rest of the nation, ${ }_{1}^{22}$ which has been associated with lower socioeconomic status, a greater proportion of black residents, higher prevalence of chronic disease, and underutilization of healthcare services. ${ }^{17,23}$ Patterns of regional disparities in stroke mortality seem to be similar to those in hypertension prevalence in Korea (Figure 5). Considering the proven effect of risk-factor control, especially hypertension control, ${ }_{1}^{24}$ for preventing stroke deaths, the observed association between regional disparities in stroke mortality and hypertension prevalence gives us a guidance for resolving such disparities.

\section{Risk factors}

High-risk alcohol intake, hypertension, diabetes, and atrial fibrillation were more prevalent in the stroke population than in the general population (Table 2). In the general population, smoking was the most prevalent risk factor, followed by hypertension, high-risk alcohol intake, diabetes, hypercholesterol-

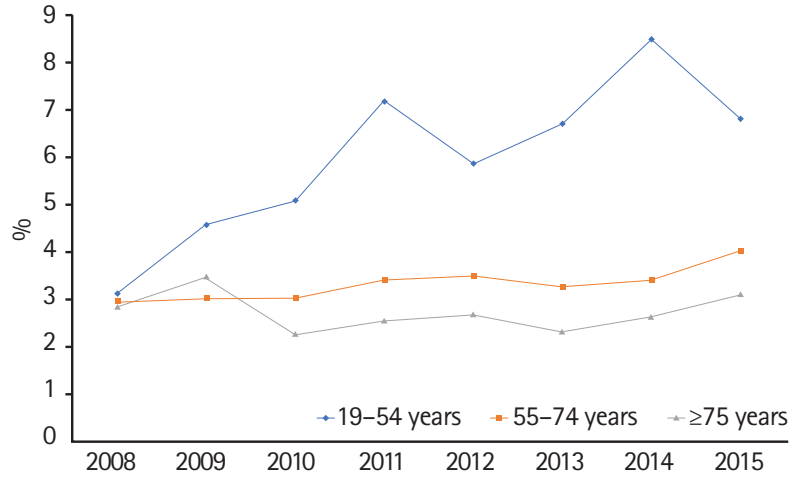

Figure 7. Age-standardized prevalence* of obesity ${ }^{+}$in the stroke population (adults aged $\geq 19$ years). *Standardization was made based on the 2005 Population and Housing Census of Korea. Prevalence of obesity was estimated using the Korea National Health and Nutrition Examination Survey (KNHANES) database from 2008 to 2014. ${ }^{+}$Obesity was defined as a body mass index $(\mathrm{BMI})>30$ according to the World Health Organization classification. BMI was calculated as weight in kilograms divided by height in square meters.

emia, obesity, and atrial fibrillation. In the stroke population, hypertension was most common, followed by diabetes, highrisk alcohol intake, smoking, atrial fibrillation, hypercholesterolemia, and obesity.

The prevalence of current smoking is much higher in Korea than the US ( $24 \%$ vs. $15 \%$ in all, $43 \%$ vs. $17 \%$ in men, and $6 \%$ vs. $14 \%$ in women). ${ }^{17}$ Smoking prevalence in men decreased by a third from 1998 to 2014 (Figure 6A). Smoking prevalence in women, however, did not decrease. Regarding high-risk alcohol intake, its prevalence was three times higher in men than women and was higher in both sexes in Korea compared to global data (21\% vs. $16 \%$ in men and $7 \%$ vs. $4 \%$ in women) (Table 2). ${ }^{25}$ Over the past 10 years, the prevalence of high-risk alcohol intake did not change in men, but has increased gradu- 
Table 3. Population-attributable risk for stroke by age group* and sex

\begin{tabular}{|c|c|c|c|c|}
\hline & \multicolumn{4}{|c|}{ Population-attributable risk (\%) } \\
\hline & Smoking ${ }^{+}$ & Obesity ${ }^{\ddagger}, \S$ & Hypertension ${ }^{\S}$ & Diabetes \\
\hline \multicolumn{5}{|l|}{ Male } \\
\hline Young age & 45.1 & 4.0 & 18.0 & 8.6 \\
\hline Middle age & 37.4 & 1.8 & 29.0 & 19.1 \\
\hline Old age & 16.7 & 8.7 & 22.8 & 14.4 \\
\hline \multicolumn{5}{|l|}{ Female } \\
\hline Young age & 5.9 & 2.8 & 14.3 & 6.6 \\
\hline Middle age & 7.7 & -0.1 & 34.1 & 16.9 \\
\hline Old age & -1.0 & -0.8 & 24.4 & 9.6 \\
\hline
\end{tabular}

$\mathrm{OR}$, odds ratio.

*Age group was defined as follows: young age, 19-54 years (for smokers, 19-44 years); middle age, 55-74 years (for smokers, 45-64 years); old age, $\geq 75$ years (for smokers, $\geq 65$ years); ${ }^{\dagger}$ Population-attributable risk (PAR) of smoking was quoted from Park et al. ${ }^{32} ;{ }^{*}$ Obesity was defined as body mass index $>30 \mathrm{~kg} / \mathrm{m}^{2}$ according

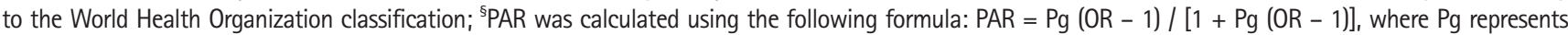
prevalence of risk factors in the general population, estimated from the population $\geq 19$ years of age in the 3th, 4th, and 5th Korea National Health and Nutrition Examination Survey (KNHANES) database (2005-2012) for obesity, and the 5th and 6th KNHANES database (2010-2014) for hypertension and diabetes.

ally in women (Figure 6B).

The prevalence of obesity defined as body mass index (BMI) $\geq 30$ is increasing slightly in general and stroke population (see Table 7-1 and Table 7-7 of Stroke Statistics in Korea $2018^{9}$ for details). This increase is mostly attributable to the increase in those aged 19 to 54 years, and similar findings were observed in the US (Figure 7 in this article and Table 7-2 of Stroke Statistics in Korea 20189). ${ }^{26}$

The prevalence of hypertension in 2007 did not differ from that in 2014 in the general and stroke populations (for details, see Figure 8-2 and 8-5 in Stroke Statistics in Korea 2018 $)$. However, during this period, the prevalence in the general population increased slightly from 2007 to 2009, then returned to the level of 2007 in 2014. The crude number of patients diagnosed with hypertension tripled from 2002 to 2016 in Korea. ${ }^{27}$ The prevalence of diabetes mellitus increased slightly between 2007 and 2014: $7.7 \%$ to $8.0 \%$ in the general population and $30.7 \%$ to $32.4 \%$ in the stroke population (for details, see Figure 9-2 and 9-5 in Stroke Statistics in Korea 2018 $)$. The prevalence of diabetes among Korean adults is expected to rise up to $11.4 \%$ in 2030 with aging of the population. ${ }^{28}$ The prevalence of hypercholesterolemia ( $\geq 240 \mathrm{mg} / \mathrm{dL}$ ) was $7.8 \%$ in the general population and $7.2 \%$ in patients with acute ischemic stroke (for details, see Table 10-1 and 10-4 in Stroke Statistics in Korea 2018 ${ }^{9}$. As in the US and Europe, the prevalence of atrial fibrillation is increasing gradually, and this tendency is more marked in the stroke population than in the general population (for details, see Table 11-1 and Figure 11-1 in Stroke Statistics in Korea 20189). 17,29,30

Population-attributable risk was estimated for individual risk factors according to age groups and sex (Table 3$)$. In young and middle-aged men, smoking is the most important

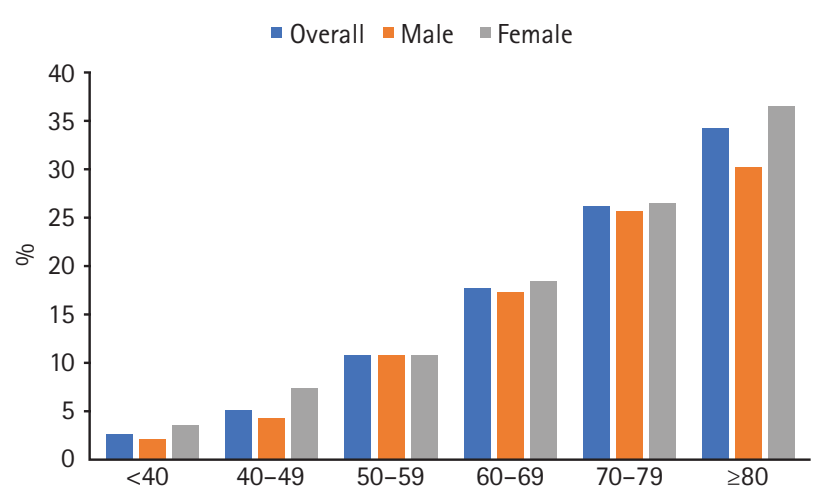

Figure 8. Prevalence of atrial fibrillation in patients with acute ischemic stroke. Calculated using the Clinical Research Collaboration for Stroke in Korea (CRCS-K) database from January 2010 to March 2015 in all age groups.

risk factor, and in young and middle-aged women, hypertension is most important. In the elderly, hypertension is most important in both sexes. These findings are similar to those of the previous study using the CRCS-K database between 2008 and 2010 and the 4th KNHANES (2008 to 2010), with the exception of the lower contribution of hypertension in young women (14.3\% vs. $5.4 \%) .{ }^{31}$ The prevalence of atrial fibrillation in the stroke population is increasing with age, and more prominently so in women (Figure 8), which may reflect a greater contribution of atrial fibrillation to stroke incidence with aging in women than men. ${ }^{32,33}$

\section{Stroke characteristics}

According to the nationwide data from the ASQAP, ischemic stroke is the most common type of stroke, accounting for 


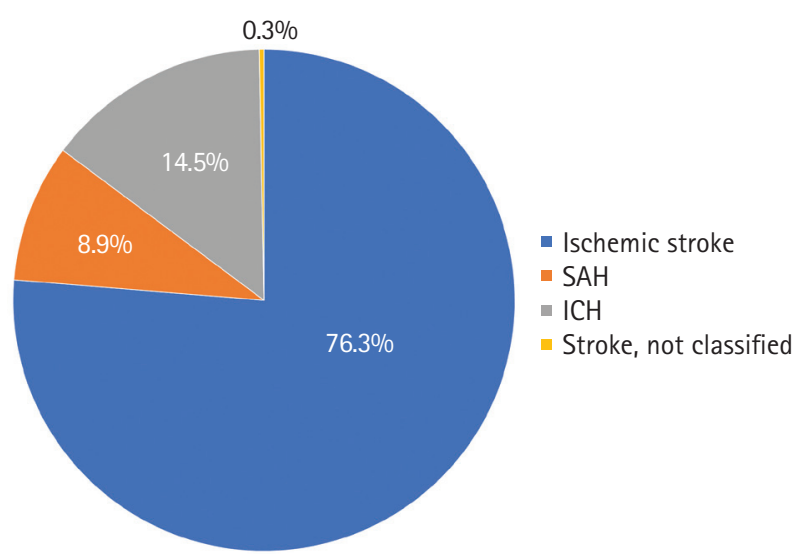

Figure 9. Stroke type in Korea. Obtained from the 5th (2013) and 6th (2014) Acute Stroke Quality Assessment Program (ASOAP) database. SAH, subarachnoid hemorrhage; ICH, intracerebral hemorrhage.

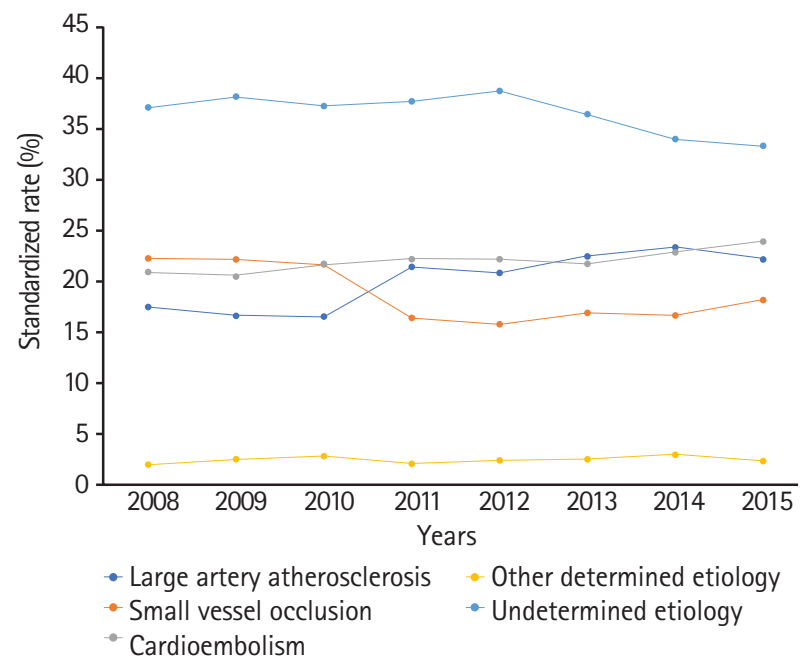

Figure 10. Secular trends in ischemic stroke subtypes. Ischemic stroke subtype was evaluated using the Clinical Research Collaboration for Stroke in Korea (CRCS-K) database from April 2008 to March 2015. The magnetic resonance imaging-based diagnostic algorithm for acute ischemic stroke subtype classification (MAGIC) ${ }^{37}$ was applied to all patients with stroke hospitalized since July 2011.

about $76 \%$ of stroke admissions, followed by ICH and SAH (Figure 9). This proportion of ischemic stroke is slightly lower than the $80 \%$ of the US, ${ }^{34}$ but similar to that of European countries. ${ }^{35}$ Regarding ischemic stroke subtypes, according to the CRCS-K data, about 37\% of patients with ischemic stroke had large artery atherosclerosis (LAA), followed by cardioembolism (22\%) and small vessel occlusion (SVO, 18\%). Classification of ischemic stroke subtypes were based on the MRI-based diagnostic algorithm for acute ischemic stroke subtype classification (MAGIC), a modification of The Trial of Org 10172 in Acute Stroke Treatment classification. ${ }^{36}$ Analysis of secular trends in ischemic stroke subtypes showed a slight decrease of
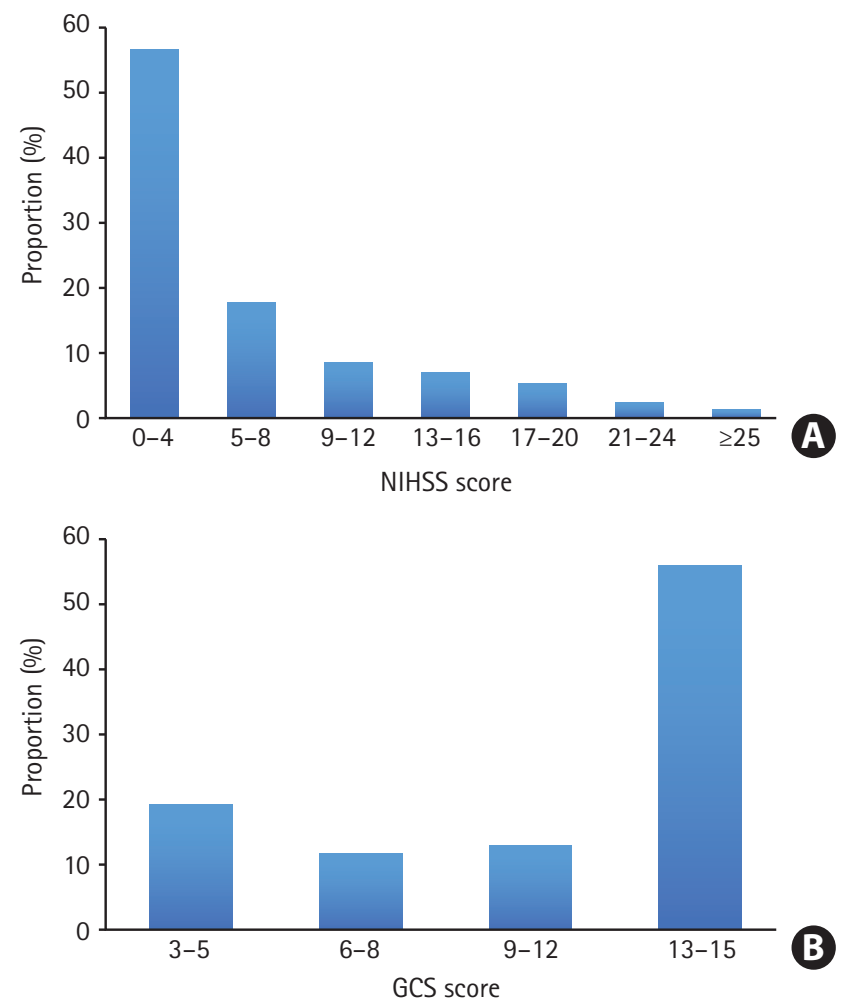

Figure 11. Stroke severity at admission in (A) acute ischemic* and (B) hemorrhagic stroke. ${ }^{+}$NIHSS, National Institutes of Health Stroke Scale; GCS, Glasgow Coma Scale. *Stroke Severity data (NIHSS scores) in patients with acute ischemic stroke were obtained from the Clinical Research Collaboration for Stroke in Korea (CRCS-K) database from April 2008 to March 2015; 'Stroke Severity data (GCS scores) in patients with acute hemorrhagic stroke were obtained from the 5th (2013) and 6th (2014) Acute Stroke Quality Assessment Program (ASOAP) database.

LAA, an increase of cardioembolism, and a decrease of SVO between 2008 and 2015 (Figure 10). These trends were not much different from those reported in another study from Korea between 2002 and $2010^{37}$ and in a study from Canada between 2002 and 2012.38

Stroke severity was mild in a majority of patients with stroke according to the ASOAP database (Figure 11), which was similar to previous reports from the US. ${ }^{39,40}$ About half of ischemic and hemorrhagic stroke cases had NIHSS of four or lower (see Supplemental Table 17-1 and 17-2 of Stroke Statistics in Korea $2018^{9}$ for details). Severe neurological deficits at symptom onset (NIHSS scores of 25 or higher) were more common in hemorrhagic stroke than in ischemic stroke (13.9\% vs. $1.5 \%)$.

Regarding the anatomical location of ischemic stroke lesions, the cortex was the most common location; about half of the patients with ischemic stroke had cortical lesions. Other common locations were the corona radiata, putamen-internal capsule, pons, cerebellum, and thalamus, in order (see Table 18-1 and 18-3 of 
Table 4. Summary of acute management and secondary prevention

\begin{tabular}{|c|c|}
\hline Variable & Value \\
\hline \multicolumn{2}{|l|}{ Time to arrival, } \\
\hline Any stroke (hr) & $4.6(1.4-20.8)$ \\
\hline Ischemic stroke (hr) & $6.2(1.8-24.0)$ \\
\hline Hemorrhagic stroke (hr) & $2.4(0.9-7.6)$ \\
\hline \multicolumn{2}{|l|}{ Within 3 hr, any stroke (\%) } \\
\hline Overall & 41.8 \\
\hline Male & 40.8 \\
\hline Female & 42.9 \\
\hline Ambulance utilization rates in any stroke $(\%)^{+}$ & 56.0 \\
\hline \multicolumn{2}{|l|}{ Reperfusion therapy in ischemic stroke $(\%)^{+}$} \\
\hline IVT & 10.7 \\
\hline EVT & 3.6 \\
\hline Hospitals providing stroke unit care $(\%)^{+}$ & 34.4 \\
\hline \multicolumn{2}{|c|}{ Antithrombotics at admission in ischemic stroke $(\%)^{\ddagger}$} \\
\hline Antiplatelets & 85.3 \\
\hline Anticoagulants & 12.9 \\
\hline No antithormbotics & 8.2 \\
\hline \multicolumn{2}{|c|}{ Antithrombotics at discharge in ischemic stroke $(\%)^{\dagger}$} \\
\hline Antiplatelets & 78.2 \\
\hline Anticoagulants & 17.5 \\
\hline No antithormbotics & 8.3 \\
\hline \multicolumn{2}{|l|}{ PDC during first $1 \mathrm{yr}$ after index ischemic stroke $(\%)^{\S}$} \\
\hline Lipid-lowering medications & 75.1 \\
\hline Diabetes medications & 73.9 \\
\hline Antihypertensives & 82.2 \\
\hline \multicolumn{2}{|c|}{ Operations and interventions in ischemic stroke $(\%)^{\S}$} \\
\hline CEA & 0.9 \\
\hline CVAl & 2.9 \\
\hline Intracerebral anastomosis & 0.6 \\
\hline Intracranial artery intervention & 1.2 \\
\hline Craniectomy or craniotomy & 1.4 \\
\hline
\end{tabular}

Values are presented as median (interquartile range).

IVT, intravenous thrombolysis; EVT, endovascular treatment; PDC, proportion of days covered; CEA, carotid endarterectomy; CVAl, carotid or vertebral artery stenting and/or angioplasty.

*Time to arrival was defined as the time interval between the first found abnormal and arrival at hospital; ${ }^{+}$Data were obtained from the 5th (2013) and 6th (2014) Acute Stroke Quality Assessment Program (ASQAP) database; ${ }^{*}$ Information on antithrombotics at admission and discharge was obtained from the Clinical Research Collaboration for Stroke in Korea (CRCS-K) database from April 2008 to March 2015; ${ }^{\S}$ Information on PDC, operations, and interventions was obtained from the National Health Insurance Service (NHIS)-CRCS-K matching database from January 2011 to November 2013.
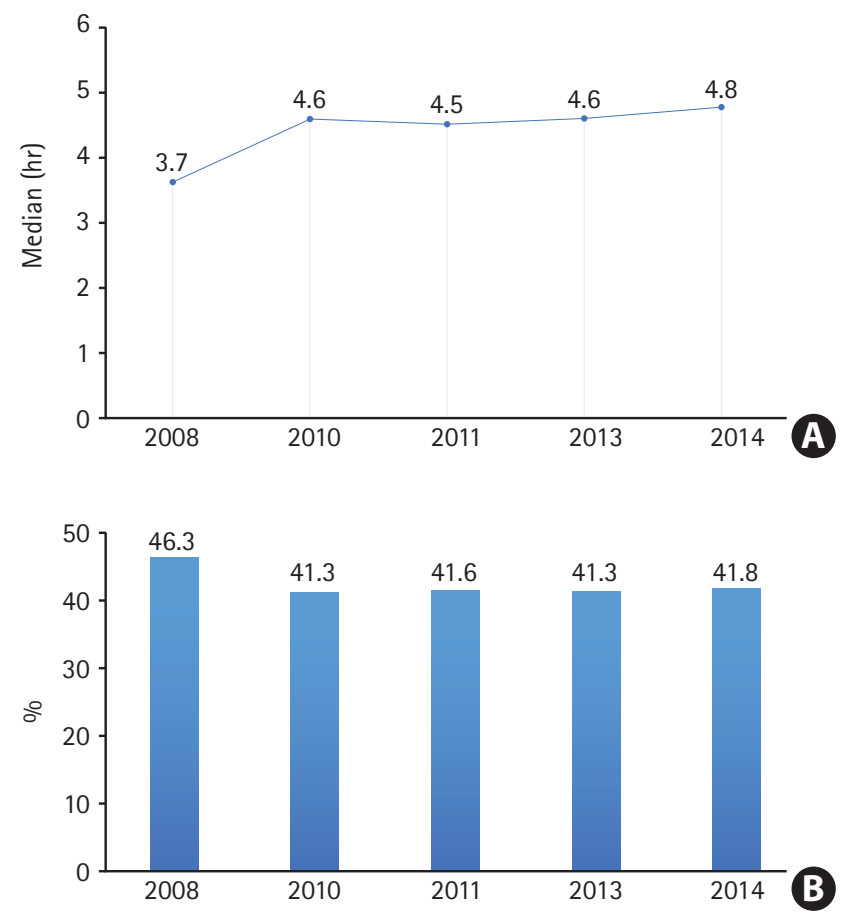

Figure 12. Secular trends of (A) onset-to-arrival time and (B) proportions of patients with stroke arriving within 3 hours from onset. Time to arrival and proportions of patients with stroke by arrival time were obtained from the Acute Stroke Quality Assessment Program (ASQAP) database from 2nd (2008) to 6th (2014).

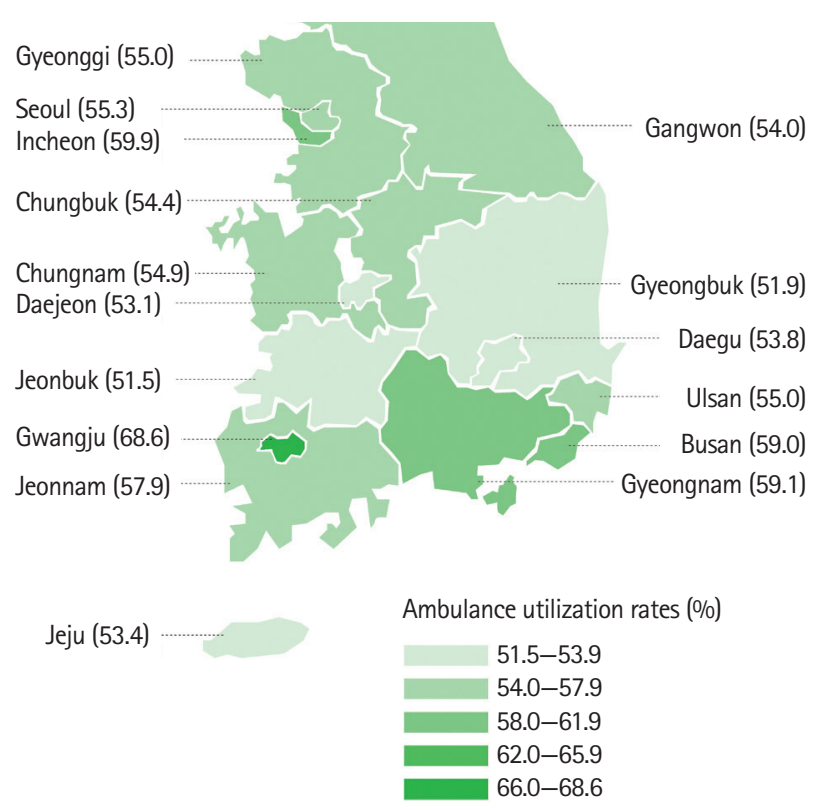

Figure 13. Ambulance utilization rates among patients with stroke by region. Ambulance utilization rates were obtained from the 5th (2013) and 6th (2014) Acute Stroke Quality Assessment Program (ASOAP) database. 


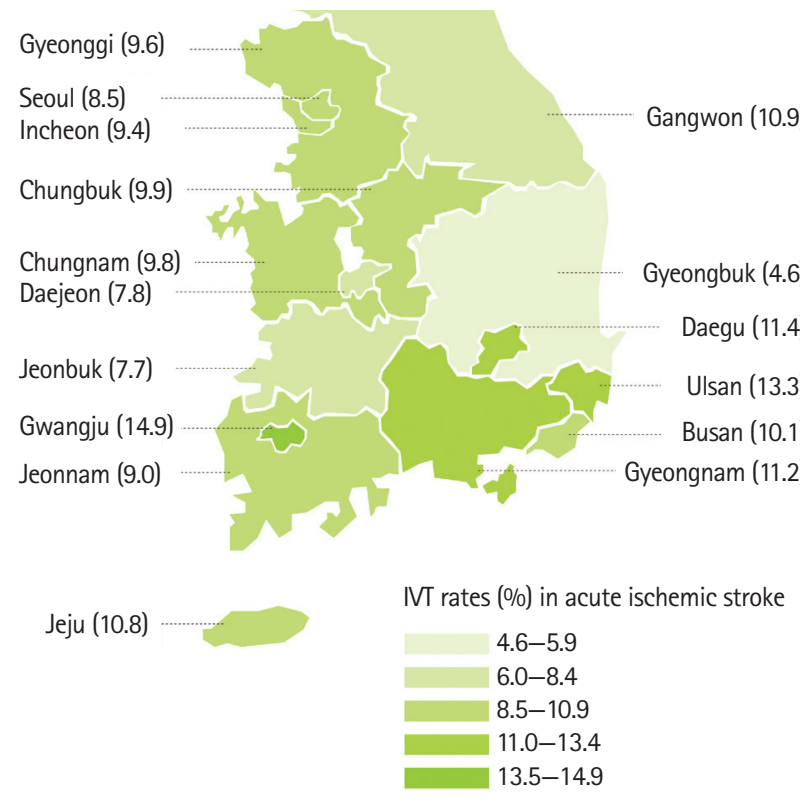

Figure 14. Intravenous thrombolysis (IVT) rates by region. IVT rates were calculated using the 5th (2013) and 6th (2014) Acute Stroke Quality Assessment Program (ASOAP) database.

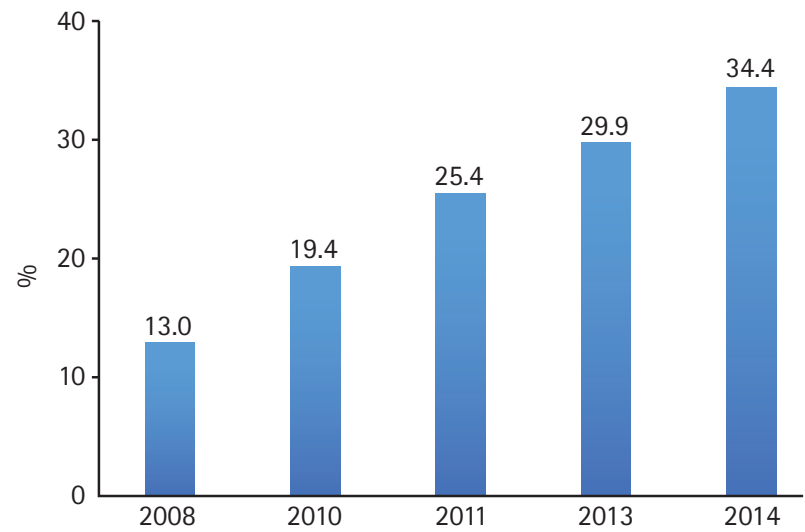

Figure 15. Secular trends in proportions of hospitals with stroke unit care. Information on hospitals providing stroke unit care was obtained from the Acute Stroke Quality Assessment Program (ASQAP) database from 2nd (2008) to 6th (2014).

Stroke Statistics in Korea $2018^{9}$ for details). Older ( $\geq 75$ years) patients with ischemic stroke were more likely to have ischemic lesions involving the cortex and corona radiata, whereas younger ( $<55$ years) patients were more likely to have medullary and cerebellar lesions. More than half (57.3\%) of cases with acute ischemic stroke had lesions in a middle cerebral artery territory.

\section{Acute management and secondary prevention}

Approximately $42 \%$ of patients with stroke arrive to the hospi-

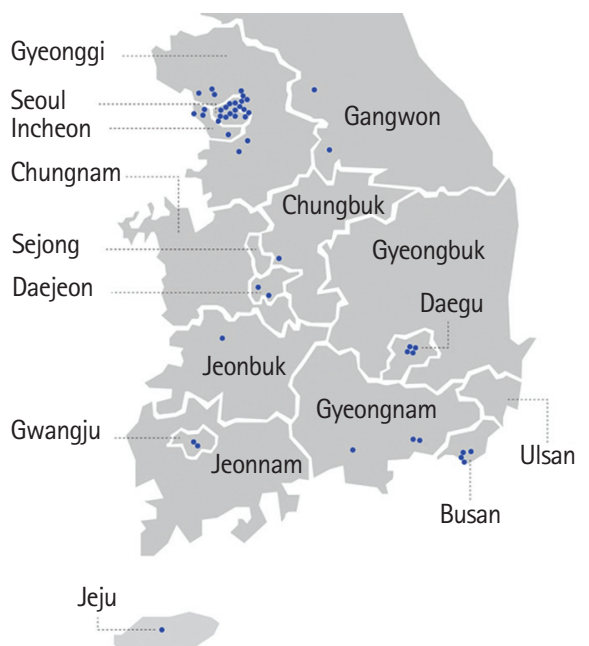

Figure 16. Distribution of hospitals with stroke units certified by the Korean Stroke Society in 2016.

tal within 3 hours of symptom onset, and 55\% within 6 hours of onset (Table 4 and Figure 12). Compared with the US, the median time from symptom onset to arrival is longer in Korea, especially for ischemic stroke (2.3 vs. 4.6 hours for all strokes and 2.8 vs. 6.2 hours for ischemic stroke). ${ }^{41}$ Unfortunately, secular trends of onset-to-arrival time did not improve from 2008 to 2014 . Slightly more than half of patients (56\%) used an ambulance to reach an emergency room, a rate lower than that of other Organisation for Economic Co-operation and Development $(\mathrm{OECD})$ countries (58\% to $79 \%){ }_{1}^{41-44}$ and the ambulance utilization rates varied markedly by region (Figure 13). Greater involvement of emergency medication systems (EMS) into stroke systems of care, such as advance notification to the receiving hospitals by EMS, reduces treatment delay and increases the likelihood of being treated with reperfusion therapy. ${ }^{45-47}$

Regarding reperfusion therapy, $1 / 10$ and $1 / 30$ acute ischemic stroke patients received intravenous thrombolysis (IVT) and endovascular treatment (EVT), respectively, during 2013 and 2014 (Table 4). The IVT rate in Korea is higher than that in the US (7.0\% in 2010 to 2011) $)^{48}$ and most European countries, and is similar to or slightly lower than that in the United Kingdom (UK), Germany, Netherlands, Finland, and Austria. ${ }^{49,50}$ The EVT rate is not different from that of the US (3.3\% in 2016). ${ }^{51}$ When looking into the secular trends, the proportions of patients receiving IVT only, EVT only, and both IVT and EVT increased between 2008 and 2014 (for details, see Figure 20-2 in Stroke Statistics in Korea $2018^{9}$ ). IVT rates varied by region; the highest rate was 15\% in Gwangju but less than 8\% in Gyeongbuk, Jeonbuk, and Daejeon (Figure 14). Efforts for reducing such disparities are needed at societal and governmental levels. 
Table 5. Case fatality* of acute ischemic stroke according to stroke unit care

\begin{tabular}{lcc}
\hline & $\begin{array}{c}\text { Patients admitted to hospitals providing } \\
\text { stroke unit care }(n=8,789)\end{array}$ & $\begin{array}{c}\text { Patients admitted to hospitals not providing } \\
\text { stroke unit care }(n=6,230)\end{array}$ \\
\hline In-hospital death (\%) & 3.6 & 4.4 \\
Death within 1 mo after discharge (\%) & 5.7 & 7.2 \\
Death within 1 yr after discharge (\%) & 13.7 & 16.8 \\
\hline
\end{tabular}

*Case fatality was estimated using the 5th (2013) and 6th (2014) Acute Stroke Quality Assessment Program (ASOAP) database.
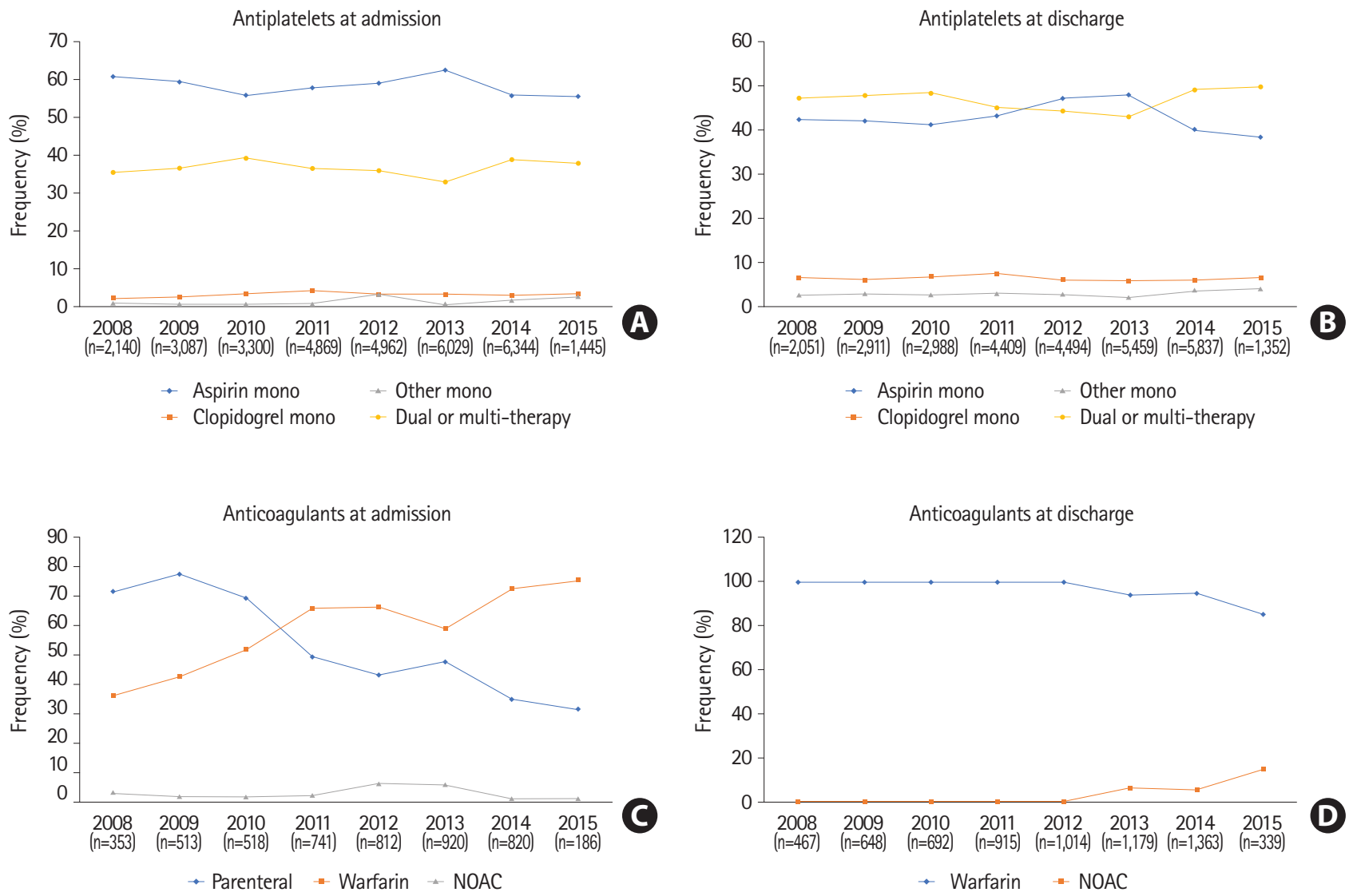

Figure 17. Antiplatelet and anticoagulant prescription for ischemic stroke or transient ischemic attack at admission and discharge. Data on antiplatelet and anticoagulant prescription were obtained from the Clinical Research Collaboration for Stroke in Korea (CRCS-K) database from April 2008 to March 2015. NOAC, non-vitamin K antagonist oral anticoagulants. (A) Antiplatelets at admission. (B) Antiplatelets at discharge. (C) Anticoagulants at admission. (D) Anticoagulants at discharge.

The Korean Stroke Society proposed the standards for stroke unit care in 2007, and started a stroke unit certification program in 2012. The number of hospitals providing stroke unit care increased from 25 (13.0\% of acute care hospitals) in 2008 to 65 (34.4\%) in 2014 (Figure 15). However, the reimbursement of stroke unit care by NHIS began in the late 2017, and the reimbursement price is still very low. This is hampering the nationwide expansion of stroke unit care, and the distribution of acute care hospitals providing stroke unit care inclines toward big cities (Figure 16). Only about one-third of patients with stroke received stroke unit care in 2014. This proportion is similar to that across Europe (30\%), higher than that in Canada (23\%), but much lower than that in Australia (67\%) and other European countries (Germany, 77\%; UK, 83\%; Sweden, $88 \%)^{50,52,53}$ In terms of case fatality, patients admitted to hospitals providing stroke unit care showed lower in-hospital death as well as 1-month and 1-year case fatality (Table 5). Therefore, further efforts for dissemination of stroke unit care, such as raising the reimbursement price and introducing stroke unit care into a major component of the hospital accreditation 
Table 6. Secular trends in quality of care for acute ischemic stroke

\begin{tabular}{lllll}
\hline Quality of stroke care & 2010 & 2011 & 2013 & 2014 \\
\hline $\begin{array}{l}\text { IV tPA in patients who arrived }<3.5 \mathrm{hr} \text { after symptom onset, treated } \\
\leq 4.5 \mathrm{hr}(\%)\end{array}$ & 81.0 & 78.1 & 79.7 & 76.8 \\
IV tPA door-to-needle time $\leq 60$ min (\%) & 61.1 & 67.3 & 81.9 & 84.4 \\
Antithrombotic agents $<48 \mathrm{hr}$ after admission (\%) & 96.4 & 99.4 & 99.8 & 99.97 \\
Antithrombotic agents at discharge (\%) & 84.9 & 84.7 & 87.5 & 90.6 \\
Anticoagulation at discharge in patients with atrial fibrillation (\%) & 63.2 & 68.4 & 72.5 & 80.3 \\
\hline
\end{tabular}

IV tPA, intravenous infusion of tissue plasminogen activator.

*Data on quality indicators were obtained from the Acute Stroke Quality Assessment Program (ASQAP) database from 2nd (2008) to 6th (2014).

Table 7. Case fatality* of stroke

\begin{tabular}{lcccc} 
& Any stroke $(n=19,469)$ & Ischemic stroke $(n=14,834)$ & ICH $(n=2,823)$ & SAH $(n=1,750)$ \\
\hline No. of events & 5,677 & 3,909 & 1,153 & 580 \\
At $2 \mathrm{wk}, \%$ & $7.2(6.8-7.6)$ & $3.7(3.4-4.0)$ & $17.5(16.1-18.9)$ & $20.4(18.5-22.3)$ \\
At $1 \mathrm{mo} \%$ & $9.4(9.0-9.8)$ & $5.2(4.8-5.5)$ & $21.6(20.1-23.2)$ & $25.1(23.1-27.2)$ \\
At $3 \mathrm{mo} \%$ & $12.5(12.0-12.9)$ & $8.0(7.6-8.4)$ & $26.2(24.6-27.9)$ & $27.5(25.4-29.6)$ \\
At $6 \mathrm{mo} \%$ & $15.0(14.5-15.5)$ & $10.7(10.2-11.2)$ & $28.6(26.9-30.2)$ & $28.6(26.5-30.7)$ \\
At $1 \mathrm{yr}, \%$ & $18.6(18.1-19.1)$ & $14.6(14.1-15.2)$ & $31.7(30.0-33.5)$ & $30.1(27.9-32.2)$ \\
At 3 $\mathrm{yr}_{1} \%$ & $27.0(26.4-27.6)$ & $24.0(23.3-24.7)$ & $38.7(36.9-40.5)$ & $32.5(30.3-34.7)$ \\
\hline
\end{tabular}

$\mathrm{ICH}$, intracerebral hemorrhage; SAH, subarachnoid hemorrhage.

*Numbers are cumulative incidence of deaths among hospitalized stroke patients by percentage and were calculated using the Kaplan-Meier method based on the 5th (2013) and 6th (2014) Acute Stroke Quality Assessment Program (ASOAP) database.

program, are urgent at governmental and societal levels.

The frequency of patients with ischemic stroke or transient ischemic attack who received antithrombotic therapy at admission was about $92 \%$ (antiplatelet in 85\% and anticoagulant in 12\%; overlap was allowed) according to the CRCS-K database (Figure 17). This frequency of $92 \%$ was similar to that of the US (95.1\%) ${ }^{41}$ and Taiwan (94.8\%). ${ }^{54}$ Regarding antiplatelet therapy, aspirin monotherapy was most common at admission (58.9\%) and dual or multiple antiplatelet therapy was most common at discharge (46.5\%). Regarding anticoagulant therapy, warfarin was the most common medication at admission and discharge (59.8\% and 97.1\%, respectively) until 2015.

For assessment of adherence to secondary preventive medication, the proportion of days covered (PDC) was calculated at 1 year after index stroke. One-year PDC was obtained using the NHIS-CRCS matching database by dividing the number of prescription days by 365 days. PDC of medications for dyslipidemia, diabetes, and hypertension was assessed per medical condition. Patients who deceased at the point of 1 year after discharge or whose mortality was unknown were excluded from the analysis (15.1\%). However, the proportion of patients who were lost to follow-up was minimized by comprehensive assessment of claim data, regardless of the hospital. PDCs for dyslipidemia and diabetes were suboptimal (Table 4). However, PDC for hypertension was relatively high. Compared to a previous study from the US, ${ }^{55}$ using the AHA Get With The Guidelines-Stroke database, adherence was much lower in Korea ( $91 \%$ vs. 75\% for lipid-lowering drugs, 91\% vs. 74\% for antidiabetic drugs, and $92 \%$ vs. $82 \%$ for antihypertensive drugs). Furthermore, the PDCs in this report might be overestimated because the NHIS-CRCS matching database was originated from patients with stroke who were admitted to university hospitals or regional stroke centers, which were motivated to improve the quality of stroke care.

\section{Quality of care and outcome}

Regarding the quality of care, all quality indicators in acute ischemic stroke improved continuously from 2008 to 2014 (Table 6), and this improvement could be attributed to various efforts, including the ASOAP by HIRA, stroke unit certification by the Korean Stroke Society, and establishment of regional comprehensive stroke centers by Ministry of Health and Welfare. ${ }^{56}$ Regarding the outcomes, 1-month case fatality was 9.4\% for all strokes and 5.2\% for ischemic stroke in Korea (Table 7), which were lower than those of other developed countries; the 
Table 8. Fracture* and bleeding ${ }^{\dagger}$ after acute ischemic stroke

\begin{tabular}{|c|c|c|}
\hline & Cumulative incidence of fracture at $1 \mathrm{yr}(\%)$ & Cumulative incidence of bleeding at $1 \mathrm{yr}(\%)$ \\
\hline Total & $4.67(4.27-5.06)$ & $8.89(8.36-9.41)$ \\
\hline \multicolumn{3}{|l|}{ Sex } \\
\hline Female & $7.46(6.69-8.23)$ & $9.39(8.54-10.23)$ \\
\hline Male & $2.75(2.35-3.15)$ & $8.54(7.87-9.21)$ \\
\hline \multicolumn{3}{|l|}{ Age (yr) } \\
\hline$<55$ & $1.64(1.08-2.20)$ & $5.70(4.68-6.72)$ \\
\hline $55-74$ & $3.85(3.34-4.35)$ & $8.48(7.76-9.20)$ \\
\hline$\geq 75$ & $7.76(6.86-8.66)$ & $11.32(10.28-12.36)$ \\
\hline \multicolumn{3}{|l|}{ BMI $\left(\mathrm{kg} / \mathrm{m}^{2}\right)$} \\
\hline$<18.5$ & $6.88(4.67-9.10)$ & $16.61(13.46-19.75)$ \\
\hline $18.5-23.0$ & $4.91(4.23-5.59)$ & $9.67(8.77-10.58)$ \\
\hline $23.0-25.0$ & $4.56(3.79-5.34)$ & $8.26(7.25-9.27)$ \\
\hline $25.0-30.0$ & $3.62(2.94-4.30)$ & $6.62(5.73-7.52)$ \\
\hline$\geq 30.0$ & $7.18(4.62-9.75)$ & $6.78(4.31-9.26)$ \\
\hline \multicolumn{3}{|l|}{ GFR $\left(\mathrm{mL} / \mathrm{min} / 1.73 \mathrm{~m}^{2}\right)^{+}$} \\
\hline$\geq 90$ & UA & $6.84(6.15-7.53)$ \\
\hline $60-90$ & UA & $8.10(7.29-8.92)$ \\
\hline $30-60$ & UA & $13.83(12.11-15.54)$ \\
\hline$<30$ & UA & $30.54(25.10-35.98)$ \\
\hline \multicolumn{3}{|c|}{ Antithrombotics at discharge } \\
\hline Warfarin & $4.52(3.59-5.45)$ & 10.02 (8.69-11.34) \\
\hline Antiplatelets & $4.75(4.31-5.20)$ & $7.45(6.91-8.00)$ \\
\hline NOAC & $7.36(0.41-14.30)$ & $7.30(0.40-14.21)$ \\
\hline No antithrombotics & $4.27(2.64-5.89)$ & $22.46(19.47-25.46)$ \\
\hline \multicolumn{3}{|l|}{$\mathrm{mRS}$ at discharge } \\
\hline $4-5$ & $6.14(5.18-7.10)$ & $16.68(15.24-18.12)$ \\
\hline $2-3$ & $4.78(4.11-5.45)$ & $7.31(6.50-8.12)$ \\
\hline $0-1$ & $3.81(3.25-4.36)$ & $5.30(4.66-5.95)$ \\
\hline
\end{tabular}

Values are presented as $95 \%$ confidence interval.

$\mathrm{BMI}$, body mass index; GFR, glomerular filtration rate; $\mathrm{mRS}$, modified Rankin Scale.

*Defined as a composite of hip, spine, leg, forearm and arm fractures; ${ }^{+}$Defined as a composite of spinal cord and ocular bleeding, intracranial bleeding, and gastrointestinal bleeding requiring transfusion of $\geq 2$ packs of red blood cells. *, These two footnotes: cumulative incidence of fracture and bleeding was obtained from the National Health Insurance Service-Clinical Research Collaboration for Stroke in Korea (NHIS-CRCS-K) matching database from January 2011 to November 2013; ${ }^{~}$ Estimated GFR was calculated using Modification of Diet in Renal Disease (MDRD). Formula: $186 \times$ serum creatinine $^{-1.154} \times$ age $e^{-0.203} \times$ (0.742 if woman).

28-day case fatality was 17\% to $30 \%$ for all strokes and $13 \%$ to $23 \%$ for ischemic stroke in high-income countries in 2000 to $2008 .{ }^{4}$ According to the OECD Health Statistics 2018 , the 30-day case fatality for ischemic stroke was the second lowest in Korea (4.1\%), following Japan (3.1\%) among OECD countries. ${ }^{57}$ One-year case fatality was $18.6 \%$ for all strokes and $14.6 \%$ for ischemic stroke in Korea, which were comparable to those of Denmark ${ }^{58}$ but lower than those of England..$^{59}$

According to the NHIS-CRCS matching database, fracture occurs commonly after ischemic stroke. The cumulative incidence at 1 year was 1.1\% for hip fracture, 2.0\% for spine frac- ture, and 4.7\% for a composite of fractures (Table 8). The incidence of fractures increases with age and lower or higher BMI. Bleeding also occurs frequently after ischemic stroke. The cumulative incidence at 1 year was 8.9\% for a composite of bleedings and $7.1 \%$ for gastrointestinal bleeding requiring transfusion of two or more packs of red blood cells (Table 8). Incidence of bleeding increases with age, lower BMI, lower kidney function, and dependency at discharge (modified Rankin Scale score 4-5).

According to the Korean Burden of Disease study, ${ }_{1}^{60}$ cerebrovascular disease including both ischemic and hemorrhagic 


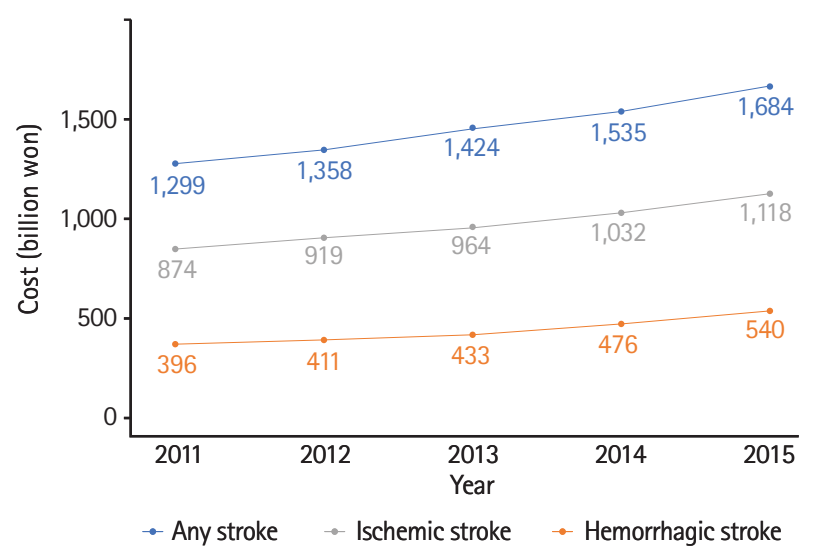

Figure 18. Direct costs (KRW) of stroke under the coverage of the National Health Insurance Services (NHIS) in Korea. Direct costs of stroke were obtained using the NHIS big data database from 2011 to 2015. 1 USD was approximately 1,200 won (KRW) on May 1, 2018.

stroke, was the second leading cause of DALYs following diabetes mellitus in 2002. In 2012, stroke took the third place following diabetes mellitus and low back pain (Table 28-2 of Stroke Statistics in Korea $2018^{9}$ for details). ${ }^{61}$ On the other hand, ischemic heart disease took the 5th place both in 2002 and 2012. According to the GBD study $2010{ }^{2}$ ischemic heart disease was the leading cause of DALYs worldwide, followed by lower respiratory infections and stroke. Stroke was the fifth cause in 1990 and the rate increased by 19\% in 2010.

In 2015, the total direct costs of stroke were 1,684 billion (KRW), of which 1,118 billion were for ischemic stroke and \#40 billion for hemorrhagic stroke ( $\$ 1,200$ is approximately $\$ 1$ [USD]) (Figure 18). Compared to 2011, the direct costs for all stroke, ischemic stroke, and hemorrhagic stroke increased by $29.6 \%, 36.2 \%$, and $27.9 \%$, respectively, in 2015 . Costs of ischemic stroke are increasing to a greater extent than those of hemorrhagic stroke and comprise two thirds of total stroke cost. However, average admission cost per episode was about two times higher for hemorrhagic stroke than for ischemic stroke (see Figure 27-2 and Supplemental Table 27-2 of Stroke Statistics in Korea $2018^{9}$ for details). ${ }^{20}$

\section{Conclusions}

Stroke is a great socioeconomic burden to our society because of its high prevalence, incidence, and related morbidities, even if mortality is declining. Modifiable risk factors are highly prevalent and differ according to age and sex. There is opportunity for improving acute stroke management in Korea, especially through reorganizing pre-hospital systems, expanding stroke unit care, and reducing regional disparities in pre-hospital and hospital care. We hope that this report will contribute to achieving these tasks.

\section{Disclosure}

The authors have no financial conflicts of interest.

\section{Acknowledgments}

We wish to thank the institutions that provided the opportunity to analyze each database used in this report. The National Health Information Database (NHIS-2015-4-022-3, NHIS2016-2-236, NHIS-2016-2-237, NHIS-2016-2-238) was provided by the NHIS of Korea and the ASOAP database is a part of the Joint Project on Quality Assessment Research by HIRA, Korea. The authors declare no conflict of interest with NHIS and HIRA.

This report was supported partially by a fund (code 2017ER 620101) from the Research of Korea Centers for Disease Control and Prevention.

\section{References}

1. Lozano R, Naghavi M, Foreman K, Lim S, Shibuya K, Aboyans $V$, et al. Global and regional mortality from 235 causes of death for 20 age groups in 1990 and 2010: a systematic analysis for the Global Burden of Disease Study 2010. Lancet 2012;380:2095-2128.

2. Murray CJ, Vos T, Lozano R, Naghavi M, Flaxman AD, Michaud C, et al. Disability-adjusted life years (DALYs) for 291 diseases and injuries in 21 regions, 1990-2010: a systematic analysis for the Global Burden of Disease Study 2010. Lancet 2012;380:2197-2223.

3. Korean Statistical Information Service (KOSIS). Annual Report on the Causes of Death Statistics. Daejeon: Statistics Korea, 2016.

4. Feigin VL, Lawes CM, Bennett DA, Barker-Collo SL, Parag V. Worldwide stroke incidence and early case fatality reported in 56 population-based studies: a systematic review. Lancet Neurol 2009;8:355-369.

5. Hong KS, Bang OY, Kang DW, Yu KH, Bae HJ, Lee JS, et al. Stroke statistics in Korea: part I. Epidemiology and risk factors: a report from the Korean Stroke Society and Clinical Research Center For Stroke. J Stroke 2013;15:2-20.

6. Hong KS, Bang OY, Kim JS, Heo JH, Yu KH, Bae HJ, et al. Stroke statistics in Korea: part II. Stroke awareness and acute stroke care: a report from the Korean Stroke Society and Clinical Research Center For Stroke. J Stroke 2013;15:67-77. 
7. Kim BJ, Park JM, Kang K, Lee SJ, Ko Y, Kim JG, et al. Case characteristics, hyperacute treatment, and outcome information from the clinical research center for stroke-fifth division registry in South Korea. J Stroke 2015;17:38-53.

8. Kim BJ, Han MK, Park TH, Park SS, Lee KB, Lee BC, et al. Current status of acute stroke management in Korea: a report on a multicenter, comprehensive acute stroke registry. Int J Stroke 2014;9:514-518.

9. Kim JY, Kang K, Kang J, Koo JS, Kim DH, Kim BJ, et al. Stroke statistics in Korea 2018: A Report from the Epidemiology Research Council of the Korean Stroke Society. Korean Stroke Society. http://www.stroke.or.kr/bbs/?code=epidemic1. 2018. Accessed December 10, 2018.

10. Kweon S, Kim Y, Jang MJ, Kim Y, Kim K, Choi S, et al. Data resource profile: the Korea National Health and Nutrition Examination Survey (KNHANES). Int J Epidemiol 2014;43:69-77.

11. Lee J, Lee JS, Park SH, Shin SA, Kim K. Cohort profile: the National Health Insurance Service-National Sample Cohort (NHIS-NSC), South Korea. Int J Epidemiol 2017;46:e15.

12. Health Insurance Review \& Assessment Service. Construction of national surveillance system for cardiovascular \& cerebrovascular diseases. Korean Center for Disease Control \& Prevention. http://www. cdc.go.kr/CDC/mobile/info/CdcKrlnfo0201.jsp?menulds=HOME001MNU1154-MNU0004-MNU1889\&fid=28\&q_type $=\& q_{\text {_ }}$ value $=\& c i d=62424 \&$ pageNum $=1.2006$. Accessed December 10, 2018.

13. Population projection and summary indicator for Korea (population items). Korean Statistical Information Service (KOSIS). http://kosis.kr/index/index.do. 2018. Accessed December 10, 2018.

14. Feigin $\mathrm{VL}$, Forouzanfar $M H$, Krishnamurthi $R$, Mensah $G A$, Connor $\mathrm{M}$, Bennett DA, et al. Global and regional burden of stroke during 1990-2010: findings from the Global Burden of Disease Study 2010. Lancet 2014;383:245-254.

15. Ahn SV. Estimating the incidence of acute myocardial infarction and stroke based on the National Health Insurance claims data in Korea. Ministry of the Interior and Safety. http://www.prism.go.kr/homepage/entire/retrieveEntireDetail.do?research_id=1351000-201600354. 2016. Accessed December 10, 2018.

16. Venketasubramanian N, Yoon BW, Pandian J, Navarro JC. Stroke epidemiology in South, East, and South-East Asia: a review. J Stroke 2017;19:286-294.

17. Benjamin EJ, Virani SS, Callaway CW, Chamberlain AM, Chang AR, Cheng $S$, et al. Heart disease and stroke statistics-2018 update: a report from the American Heart Association. Circulation 2018;137:e67-e492.

18. Ahmad OB, Boschi-Pinto $C$, Lopez AD, Murray CJL, Lozano R,
Inoue M. Age Standardization of Rates: A New WHO Standard. Geneva: World Health Organization, 2013.

19. Xu J, Murphy SL, Kochanek KD, Arias E. Mortality in the United States, 2015. NCHS Data Brief 2016;267:1-8.

20. Howard VJ, Cushman M, Pulley L, Gomez CR, Go RC, Prineas $\mathrm{RJ}$, et al. The reasons for geographic and racial differences in stroke study: objectives and design. Neuroepidemiology 2005;25:135-143.

21. Karp DN, Wolff CS, Wiebe DJ, Branas CC, Carr BG, Mullen MT. Reassessing the stroke belt: using small area spatial statistics to identify clusters of high stroke mortality in the United States. Stroke 2016;47:1939-1942.

22. Lanska DJ. Geographic distribution of stroke mortality in the United States: 1939-1941 to 1979-1981. Neurology 1993;43: 1839-1851.

23. Howard G, Anderson R, Johnson NJ, Sorlie P, Russell G, Howard VJ. Evaluation of social status as a contributing factor to the stroke belt region of the United States. Stroke 1997;28:936940.

24. Lackland DT, Roccella EJ, Deutsch AF, Fornage M, George MG, Howard $G$, et al. Factors influencing the decline in stroke mortality: a statement from the American Heart Association/ American Stroke Association. Stroke 2014;45:315-353.

25. Global Status Report on Alcohol and Health. World Health Organization. https://www.who.int/substance_abuse/publications/alcohol_2011/en. 2011. Accessed December 10, 2018.

26. Ogden $C L$, Carroll MD, Curtin LR, McDowell MA, Tabak CJ, Flegal KM. Prevalence of overweight and obesity in the United States, 1999-2004. JAMA 2006;295:1549-1555.

27. Korean Society Hypertension (KSH); Hypertension Epidemiology Research Working Group, Kim HC, Cho MC. Korea hypertension fact sheet 2018. Clin Hypertens 2018;24:13.

28. Kim DJ. The epidemiology of diabetes in Korea. Diabetes Metab J 2011;35:303-308.

29. Colilla S, Crow A, Petkun W, Singer DE, Simon T, Liu X. Estimates of current and future incidence and prevalence of atrial fibrillation in the U.S. adult population. Am J Cardiol 2013;112:1142-1147.

30. Krijthe BP, Kunst $A$, Benjamin EJ, Lip GY, Franco OH, Hofman $A_{\text {, et }}$ al. Projections on the number of individuals with atrial fibrillation in the European Union, from 2000 to 2060. Eur Heart J 2013;34:2746-2751.

31. Park $T H, K o$ Y, Lee $S J$, Lee $K B$, Lee J, Han MK, et al. Identifying target risk factors using population attributable risks of ischemic stroke by age and sex. J Stroke 2015;17:302-311.

32. Wolf PA, Abbott RD, Kannel WB. Atrial fibrillation as an independent risk factor for stroke: the Framingham Study. Stroke 1991;22:983-988. 
33. Friberg $L$, Benson $L$, Rosenqvist M, Lip GY. Assessment of female sex as a risk factor in atrial fibrillation in Sweden: nationwide retrospective cohort study. BMJ 2012;344:e3522.

34. Kleindorfer DO, Khoury J, Moomaw CJ, Alwell K, Woo D, Flaherty $M L$, et al. Stroke incidence is decreasing in whites but not in blacks: a population-based estimate of temporal trends in stroke incidence from the Greater Cincinnati/ Northern Kentucky Stroke Study. Stroke 2010;41:1326-1331.

35. Tsai CF, Thomas B, Sudlow CL. Epidemiology of stroke and its subtypes in Chinese vs white populations: a systematic review. Neurology 2013;81:264-272.

36. Ko Y, Lee $S$, Chung JW, Han MK, Park JM, Kang K, et al. MRIbased algorithm for acute ischemic stroke subtype classification. J Stroke 2014;16:161-172.

37. Jung KH, Lee SH, Kim BJ, Yu KH, Hong KS, Lee BC, et al. Secular trends in ischemic stroke characteristics in a rapidly developed country: results from the Korean Stroke Registry Study (secular trends in Korean stroke). Circ Cardiovasc Qual Outcomes 2012;5:327-334.

38. Bogiatzi C, Hackam DG, McLeod Al, Spence JD. Secular trends in ischemic stroke subtypes and stroke risk factors. Stroke 2014;45:3208-3213.

39. Reeves M, Khoury J, Alwell K, Moomaw C, Flaherty M, Woo $D$, et al. Distribution of National Institutes of Health stroke scale in the Cincinnati/Northern Kentucky Stroke Study. Stroke 2013;44:3211-3213.

40. Zahuranec DB, Lisabeth LD, Sánchez BN, Smith MA, Brown DL Garcia NM, et al. Intracerebral hemorrhage mortality is not changing despite declining incidence. Neurology 2014;82:21802186.

41. Fonarow GC, Reeves MJ, Smith EE, Saver JL, Zhao X, Olson DW, et al. Characteristics, performance measures, and inhospital outcomes of the first one million stroke and transient ischemic attack admissions in get with the guidelinesstroke. Circ Cardiovasc Qual Outcomes 2010;3:291-302.

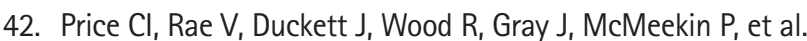
An observational study of patient characteristics associated with the mode of admission to acute stroke services in North East, England. PLoS One 2013;8:e76997.

43. Inatomi $Y$, Yonehara $T$, Hashimoto $Y$, Hirano $T$, Uchino M. Prehospital delay in the use of intravenous rt-PA for acute ischemic stroke in Japan. J Neurol Sci 2008;270:127-132.

44. Mochari-Greenberger $H$, Xian $Y$, Hellkamp AS, Schulte PJ, Bhatt DL, Fonarow GC, et al. Racial/ethnic and sex differences in emergency medical services transport among hospitalized US stroke patients: analysis of the national Get With The Guidelines-Stroke registry. J Am Heart Assoc 2015;4:e002099.

45. Abdullah AR, Smith EE, Biddinger PD, Kalenderian D,
Schwamm LH. Advance hospital notification by EMS in acute stroke is associated with shorter door-to-computed tomography time and increased likelihood of administration of tissueplasminogen activator. Prehosp Emerg Care 2008;12:426-431.

46. Derex L, Adeleine P, Nighoghossian N, Honnorat J, Trouillas P. Factors influencing early admission in a French stroke unit. Stroke 2002;33:153-159.

47. Fassbender K, Balucani C, Walter S, Levine SR, Haass A, Grotta J. Streamlining of prehospital stroke management: the golden hour. Lancet Neurol 2013;12:585-596.

48. Schwamm LH, Ali SF, Reeves MJ, Smith EE, Saver JL, Messe S, et al. Temporal trends in patient characteristics and treatment with intravenous thrombolysis among acute ischemic stroke patients at Get With The Guidelines-Stroke hospitals. Circ Cardiovasc Qual Outcomes 2013;6:543-549.

49. Scherf $S$, Limburg M, Wimmers R, Middelkoop I, Lingsma H. Increase in national intravenous thrombolysis rates for ischaemic stroke between 2005 and 2012: is bigger better? BMC Neurol 2016;16:53.

50. King's College of London for the Stroke Alliance for Europe (SAFE). The burden of stroke in Europe report. SAFE. http:// strokeeurope.eu. 2018. Accessed December 10, 2018.

51. Smith EE, Saver JL, Cox M, Liang L, Matsouaka R, Xian $Y$, et al. Increase in endovascular therapy in Get With The Guidelines: stroke after the publication of pivotal trials. Circulation 2017; 136:2303-2310.

52. Canadian Stroke Network. The Quality of Stroke Care in Canada. Ottawa, ON: Canadian Stroke Network, 2011.

53. National Stroke Foundation. National Stroke Audit: Acute Services Report 2015. Melbourne: National Stroke Foundation, 2015.

54. Hsieh Fl, Lien LM, Chen ST, Bai CH, Sun MC, Tseng HP, et al. Get With the Guidelines-stroke performance indicators: surveillance of stroke care in the Taiwan Stroke Registry: Get With the Guidelines-stroke in Taiwan. Circulation 2010;122:1116-1123.

55. Bushnell CD, Olson DM, Zhao X, Pan W, Zimmer LO, Goldstein $\mathrm{LB}$, et al. Secondary preventive medication persistence and adherence 1 year after stroke. Neurology 2011;77:1182-1190.

56. Kim J, Hwang YH, Kim JT, Choi NC, Kang SY, Cha JK, et al. Establishment of government-initiated comprehensive stroke centers for acute ischemic stroke management in South Korea. Stroke 2014;45:2391-2396.

57. OECD Health Statistics 2018. Organisation for Economic Cooperation and Development (OECD). http://www.oecd.org/ els/health-systems/health-data.htm. 2018. Accessed December 10, 2018.

58. Andersen KK, Andersen ZJ, Olsen TS. Predictors of early and late case-fatality in a nationwide Danish study of 26,818 pa- 
tients with first-ever ischemic stroke. Stroke 2011;42:28062812.

59. Bray BD, Paley L, Hoffman A, James M, Gompertz P, Wolfe $C D A$, et al. Socioeconomic disparities in first stroke incidence, quality of care, and survival: a nationwide registry-based cohort study of 44 million adults in England. Lancet Public Health 2018;3:e185-e193.
60. Yoon SJ, Bae SC, Lee SI, Chang H, Jo HS, Sung JH, et al. Measuring the burden of disease in Korea. J Korean Med Sci 2007;22:518-523.

61. Yoon J, Oh IH, Seo H, Kim EJ, Gong YH, Ock M, et al. Disability-adjusted life years for 313 diseases and injuries: the 2012 Korean Burden of Disease Study. J Korean Med Sci 2016;31 Suppl 2:S146-S157. 